\title{
Lower genomic stability of induced pluripotent stem cells reflects increased non-homologous end joining
}

\author{
Minjie Zhang ${ }^{1,2+}$, Liu Wang ${ }^{3 \dagger}$, Ke An ${ }^{1,2+}$, Jun Cai ${ }^{1}$, Guochao Li ${ }^{1,2}$, Caiyun Yang ${ }^{1}$, Huixian Liu ${ }^{1}$, Fengxia Du', \\ Xiao Han ${ }^{1,2}$, Zilong Zhang ${ }^{1,2}$, Zitong Zhao ${ }^{1,2}$, Duanqing Pei ${ }^{4}$, Yuan Long ${ }^{5}$, Xin Xie ${ }^{5}$, Qi Zhou ${ }^{3}$ and Yingli Sun ${ }^{* *}$
}

\begin{abstract}
Background: Induced pluripotent stem cells (iPSCs) and embryonic stem cells (ESCs) share many common features, including similar morphology, gene expression and in vitro differentiation profiles. However, genomic stability is much lower in iPSCs than in ESCs. In the current study, we examined whether changes in DNA damage repair in iPSCs are responsible for their greater tendency towards mutagenesis.
\end{abstract}

Methods: Mouse iPSCs, ESCs and embryonic fibroblasts were exposed to ionizing radiation (4 Gy) to introduce double-strand DNA breaks. At $4 \mathrm{~h}$ later, fidelity of DNA damage repair was assessed using whole-genome re-sequencing. We also analyzed genomic stability in mice derived from iPSCs versus ESCs.

Results: In comparison to ESCs and embryonic fibroblasts, iPSCs had lower DNA damage repair capacity, more somatic mutations and short indels after irradiation. iPSCs showed greater non-homologous end joining DNA repair and less homologous recombination DNA repair. Mice derived from iPSCs had lower DNA damage repair capacity than ESC-derived mice as well as C57 control mice.

Conclusions: The relatively low genomic stability of iPSCs and their high rate of tumorigenesis in vivo appear to be due, at least in part, to low fidelity of DNA damage repair.

Keywords: Genomic stability, DNA damage repair, iPSCs, ESCs

\section{Background}

Embryonic stem cells (ESCs) are pluripotent and could differentiate into all types of somatic cells [1]. ESCc have enormous potential in the treatment of a variety of diseases, but their clinical application has been limited by ethical controversy. In 2006, Yamanaka and colleagues overexpressed four transcription factors (Oct4, Sox2, $c-M y c$ and Klf4) in mouse somatic cells and obtained ESC-like pluripotent stem cells, termed induced pluripotent stem cells (iPSCs) [2]. iPSCs resemble ESCs in

\footnotetext{
*Correspondence: subyl@big.ac.cn; sunyl@big.ac.cn

${ }^{\dagger}$ Minjie Zhang, Liu Wang and Ke An are co-first authors and contributed equally to this work

${ }^{1}$ Key Laboratory of Genomic and Precision Medicine, China Gastrointestinal Cancer Research Center, Beijing Institute of Genomics,

Chinese Academy of Sciences, Beijing 100101, P. R. China

Full list of author information is available at the end of the article
}

morphology, gene expression profile, epigenetic status and in vitro differentiation capacity. The development of iPSCs raises new hope for personalized clinical therapy [3-5].

The four transcription factors (Oct4, Sox2, c-Myc and Klf4) that are critical for the production of iPSCs are frequently overexpressed in various cancers, and mice derived from iPSCs are prone to develop tumors [6-9]. Although only a small population of transformed cells with genetic mutations is likely to develop into tumors [10], the genomic instability of iPSCs is a major concern that could produce huge impact on their eventual clinical use [11-16].

One possible explanation for the observed greater genomic instability of iPSCs is alterations in the fidelity of DNA repair pathways. Double-stranded DNA breaks, for example, can be repaired via homologous recombination 
(HR) with high fidelity, or via non-homologous end joining (NHEJ) with lower fidelity [17-20]. In the current study, we examined whether iPSCs differ from other types of pluripotent cells in their ability to perform these types of DNA repair. Briefly, ionizing radiation was used to induce double-stranded DNA breaks in the following cells: mouse iPSCs induced using lentivirus (lv-iPSCs) or chemically with CHR99021, Repsox and forskolin (ciiPSCs) [21]; mouse ESCs; and mouse embryonic fibroblasts (MEFs) [22-26].

The experiments showed that lv-iPSCs are more likely than the other cell types to harbor genomic abnormalities, likely due to lower genomic fidelity of DNA damage repair. We also found greater genomic stability in ciiPSCs than lv-iPSCs.

\section{Methods}

\section{Cell lines and culture}

The $\mathrm{lv}$ - and ci-iPSCs were derived from female transgenic OG2 mice carrying an Oct4-GFP transgene. Both types of iPSCs and ESCs were cultured in Dulbecco's Modified Eagle Medium (DMEM; Gibco, Grand Island, NY, USA) supplemented with $15 \%$ fetal bovine serum (FBS; Gibco), 1\% MEM non-essential amino acids (Gibco), 1\% penicillin/streptomycin (Gibco), 2 mmol/L L-glutamine (Gibco), $1 \times 10^{3}$ units $/ \mathrm{mL}$ of mouse leukemia inhibitory factor (Millipore, Temecula, CA, USA) and $0.1 \mathrm{mmol} / \mathrm{L} 2$-mercaptoethanol (Gibco) [27]. The medium was changed daily, and cells were passaged every 2 days using $0.25 \%$ trypsin (Thermo Fisher Scientific, Beijing, China) [28]. MEFs were cultured in DMEM supplemented with $15 \%$ FBS, $1 \%$ non-essential amino acids and $1 \%$ penicillin/ streptomycin [29].

\section{Irradiation}

Cells were passaged 1 day before $\gamma$-irradiation (4 Gy) with a cobalt irradiator (Thermo Fisher Scientific). After the irradiation, cells were immediately returned to the incubator, and cultured for $4 \mathrm{~h}$ prior to analyses as described below.

\section{Western blotting}

To test the phosphorylation level of ATM, cells were lysed in ATM lysis buffer [20 mmol/L HEPES ( $\mathrm{pH} 7.4$ ), $150 \mathrm{mmol} / \mathrm{L} \mathrm{NaCl}, 0.2 \%$ Tween-20, $1.5 \mathrm{mmol} / \mathrm{L} \mathrm{MgCl}_{2}$, $1 \mathrm{mmol} / \mathrm{L}$ EGTA, $2 \mathrm{mmol} / \mathrm{L}$ dithiothreitol, $50 \mathrm{mmol} / \mathrm{L}$ $\mathrm{NaF}, 500 \mu \mathrm{mol} / \mathrm{L} \mathrm{NaVO}_{4}, 1 \mathrm{mmol} / \mathrm{L}$ phenylmethylsulfonyl fluoride, $0.1 \mu \mathrm{g} / \mathrm{mL}$ aprotinin and $0.1 \mu \mathrm{g} / \mathrm{mL}$ leupeptin], and centrifuged, as describe previously [30].

In assays of histone modification, cells were re-suspended in 1-mL triton extraction buffer (TEB) containing $0.5 \%$ Triton X-100 and $2 \mathrm{mmol} / \mathrm{L}$ PMSF, and then lysed on ice for $10 \mathrm{~min}$. The lysates were centrifuged at
$1500 \mathrm{~g}$ for $10 \mathrm{~min}$ at $4{ }^{\circ} \mathrm{C}$. The pellet was washed with 1.5$\mathrm{mL} \mathrm{TEB}$, re-suspended in $0.2 \mathrm{~mol} / \mathrm{L} \mathrm{HCl}$, and incubated at $4{ }^{\circ} \mathrm{C}$ overnight. Samples were centrifuged at $6500 \mathrm{~g}$ for $10 \mathrm{~min}$, after which $200-\mu \mathrm{L}$ supernatant was transferred to a new tube, and neutralized with $20-\mu \mathrm{L} 2 \mathrm{~mol} / \mathrm{L}$ $\mathrm{NaOH}$.

Samples were separated using SDS-PAGE and transferred to PVDF membranes (Millipore, Billerica, MA, USA). Blots were incubated with a primary antibody against one of the following proteins: phospho-ATM (1:1000; R\&D Systems, Minneapolis, MN, USA), $\beta$-actin (1:3000; Beyotime Biotech, Beijing, China), H3 (1:30,000; Abcam, Cambridge, MA, USA) and H3K9me3 (1:3000; Abcam). Blots were washed three times with phosphatebuffered saline (PBS), and then incubated with a horseradish peroxidase-conjugated anti-mouse secondary antibody (1:3000; Gene Tex, San Diego, CA, USA) or anti-rabbit secondary antibody (1:3000; Abcam). Protein bands of interest were visualized using an Image Quant ECL system (GE Healthcare, Piscataway, NJ, USA).

\section{Immunofluorescence labeling of $\mathrm{Y}-\mathrm{H}_{2} \mathrm{AX}$ foci}

Cells were passaged onto slides, exposed $24 \mathrm{~h}$ later to 4 Gy of $\gamma$-irradiation, and incubated at $37^{\circ} \mathrm{C}$ for $4 \mathrm{~h}$. Cells were washed with $\mathrm{PBS}$, fixed with $4 \%$ paraformaldehyde for $10 \mathrm{~min}$ at room temperature, washed again with PBS, permeabilized for 10 min using $0.05 \%$ Triton X-100 and $0.5 \% \mathrm{NP}-40$, and then washed three times ( 5 min each) in PBS. The cells were blocked for $1 \mathrm{~h}$ with $2 \%$ bovine serum albumin (BSA), and then incubated for $1 \mathrm{~h}$ at room temperature with a mouse anti- $\gamma \mathrm{H}_{2} \mathrm{AX}$ antibody (1:500; Millipore, Temecula, CA, USA). Cells were washed three times with PBS containing $0.05 \%$ Tween 20 , and then incubated with a goat anti-mouse secondary antibody (1:800; Abcam) for $1 \mathrm{~h}$ in the dark at room temperature. Cells were counterstained with $0.2 \mathrm{mg} / \mathrm{mL}$ 4',6-diamidino-2-phenylindole (DAPI, 1:2000; Sigma, Shanghai, China). Confocal images were acquired and analyzed using a TCS SP5 (Leica) microscope equipped with an HCX PL $63 \times 1.4$ CS oil-immersion objective lens.

\section{DNA extraction}

Three types of cells (lv-iPSCs, ci-iPSCs, ESCs) were digested with $0.25 \%$ trypsin and re-suspended in gelatin-coated dishes. After incubation at $37{ }^{\circ} \mathrm{C}$ for $15 \mathrm{~min}$, supernatants were transferred to $15-\mathrm{mL}$ centrifuge tubes, and cells were collected by centrifugation at $500 \mathrm{~g}$ for $5 \mathrm{~min}$ at room temperature. DNA was extracted using a QIAamp DNA Mini Kit (Qiagen, Hilden, Germany).

\section{Whole-genome re-sequencing}

Whole-genome DNA libraries suitable for sequencing using an Illumina sequencing platform were generated 
from 1- $\mu \mathrm{g}$ genomic DNA. The DNA was sheared to approximately 300-500 bp using a Covaris S220 instrument (Life Technologies, Carlsbad, CA, USA). A total of $2 \times 101$-bp paired-end reads were produced using the HiSeq 2000 DNA Sequencer.

The sequencing data were mapped to a reference mouse genomic sequence (mm9) using the Burrows-Wheeler alignment tool algorithm [31]. Unique alignment reads were retained for later analysis. Using the untreated cells as a control, single-nucleotide variations (SNVs) were collected using the "mpileup" tool in SAMTools as well as the UnifiedGenotyper in the GATK module [32, 33]. Quality recalibration and local realignment were performed using GATK tools before variation calling was performed. The following criteria were applied for calling mutations using pairwise samples: (1) the minimum coverage of variant sites had to be greater than 20 and base quality greater than 15; (2) the frequency of mutant SNVs had to be 0 in control samples and 0.2 in irradiated samples; and (3) the variant sites had to be supported by at least two reads on the forward strand and two reads on the reverse strand.

\section{RNA sequencing}

Total RNA was extracted from each cell line using TRIzol reagent and enriched for mRNA using oligo (dT) magnetic beads. Approximately 1- $\mu$ g mRNA was fragmented and electrophoresed to isolate mRNA fragments (200-250 bases). These fragments were subjected to end repair, $3^{\prime}$ terminal adenylation and adapter ligation, followed by cDNA synthesis. The resulting cDNAs were gel-electrophoresed to isolate $250-300 \mathrm{bp}$ fragments, and were sequenced using a HiSeq 2000 system (Illumina).

Sequencing reads were aligned to a reference sequence (GRCm37/mm9) using TopHat alignment software [34, 35]. Only uniquely aligned reads were used for transcript assembly, which was performed using Cufflinks software [36]. Read counts for each gene were calculated, and the expression levels of each gene were normalized using the "fragments per kilobase of exon model per million mapped" (FPKM) algorithm. Differentially expressed genes were filtered based on false discovery rate (FDR)-adjusted $P<0.05$. The profile of differentially expressed genes was visualized and analyzed using the Bioconductor function "CummeRbund" in the R program [37]. Hierarchical clustering was performed using the "heatmap" package in $\mathrm{R}$.

\section{Generation of iPSC- and ESC-derived mice}

Two cell-stage ICR embryos were electrofused to produce tetraploid embryos, and 10-15 iPSCs and ESCs were subsequently injected into the reconstructed tetraploid blastocysts. Embryos were cultured for 1 day prior to transplantation into the uterus of pseudo-pregnant mice. Caesarean sections were performed at E19.5, and the pups were fostered by lactating ICR mothers [38].

\section{Comet assay}

Mice derived from iPSCs or ESCs as well as C57 mice were treated with $4 \mathrm{~Gy}$ ionizing radiation. At $4 \mathrm{~h}$ later, bone marrow cells were isolated and re-suspended using PBS and concentrated by adding $150-\mu \mathrm{L}$ molten $0.75 \%$ low-melting-point agarose. An aliquot of concentrated cells $(60 \mu \mathrm{L})$ was then added to molten $0.8 \%$ normal-melting-point agarose on comet slides. The slides were incubated for $1-2 \mathrm{~h}$ at $4{ }^{\circ} \mathrm{C}$ with pre-chilled lysis buffer, stored in the dark at $4{ }^{\circ} \mathrm{C}$ for $20 \mathrm{~min}$, then incubated with pre-chilled electrophoresis buffer $(0.3 \mathrm{~mol} / \mathrm{L} \mathrm{NaOH}$ containing $0.5 \mathrm{~mol} / \mathrm{L}$ EDTA, pH>13.0). Gel electrophoresis was performed at $25 \mathrm{~V}$ for $20 \mathrm{~min}$ at $4{ }^{\circ} \mathrm{C}$. Slides were incubated at $4{ }^{\circ} \mathrm{C}$ for 15 min with neutralization buffer $(0.4 \mathrm{~mol} / \mathrm{L}$ Tris, $\mathrm{pH}>7.5)$, washed with $100 \%$ ethanol for 3-5 min and air-dried at room temperature. Diluted ethidium bromide (EB) solution $(20-30 \mu \mathrm{L})$ was placed onto each dried agarose circle. Slides were then read at 100 cells/sample using a fluorescence microscope equipped with CASP DNA damage analysis software.

\section{Results}

Similar gene expression profile between Iv-iPSCs and ESCs RNA-seq analysis showed that the gene expression profile of lv-iPSCs was similar to that of ESCs but not to that of MEFs (Fig. 1a), indicating iPSC pluripotency. Since genomic stability depends on DNA damage repair, we analyzed expression of the genes involved in DNA damage repair pathways. No significant differences in the expression of such genes were found between lv-iPSCs and ESCs (Fig. 1b). We further analyzed the expression of DNA repair genes that were identified during early reprogramming of iPSCs in our previous report [39] and confirmed the up-regulation of those genes at early iPSC stages (Fig. 1c). These results suggest that DNA damage repair pathways can be reprogrammed at early iPSC stages and become similar to pathways in ESCs as reprogramming continues [39].

(See figure on next page.)

Fig. 1 Gene expression profile of ESCs, Iv-iPSCs and MEFs. a Scatter plots used to identify global trends in gene expression and differences among cell lines. b Heat maps showing the expression level of DNA damage repair-associated genes in the cell lines. Blue color indicates lowest expression; fuchsia, highest. c Re-analysis of the expression of DNA damage repair-associated genes during early reprogramming 

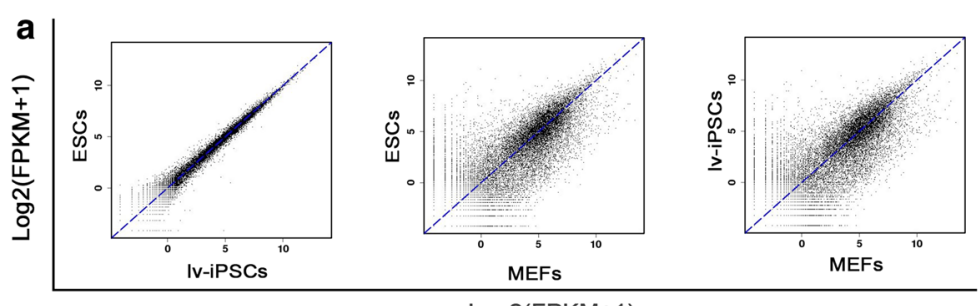

b
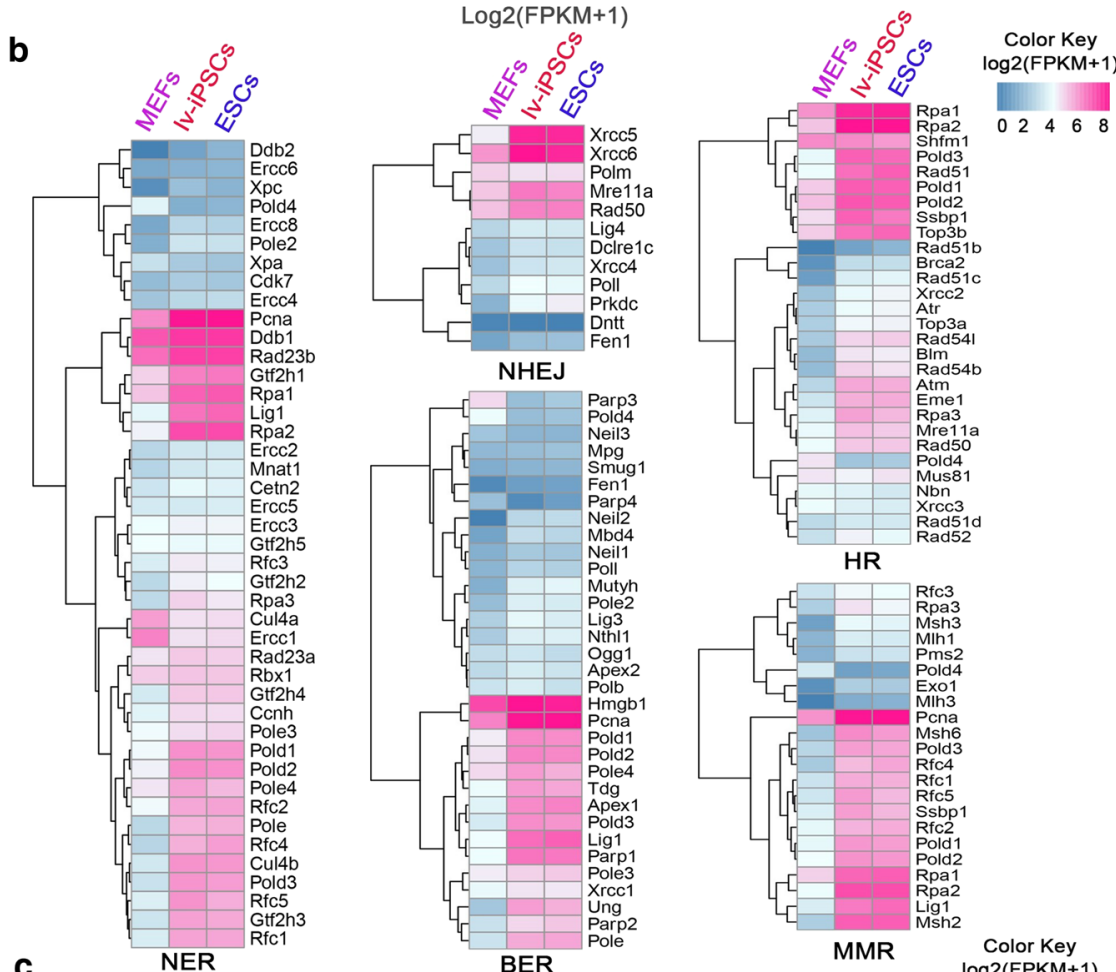
$8 x^{8} x^{\circ}$

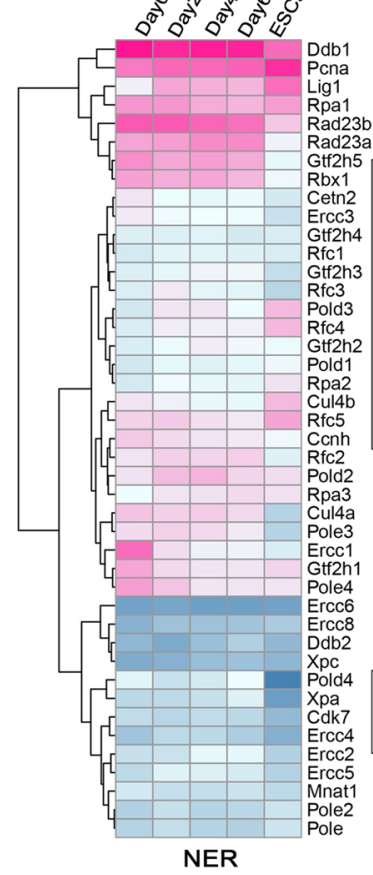

$0^{8} 0^{2} 0^{2} 0^{4} 0^{8}$
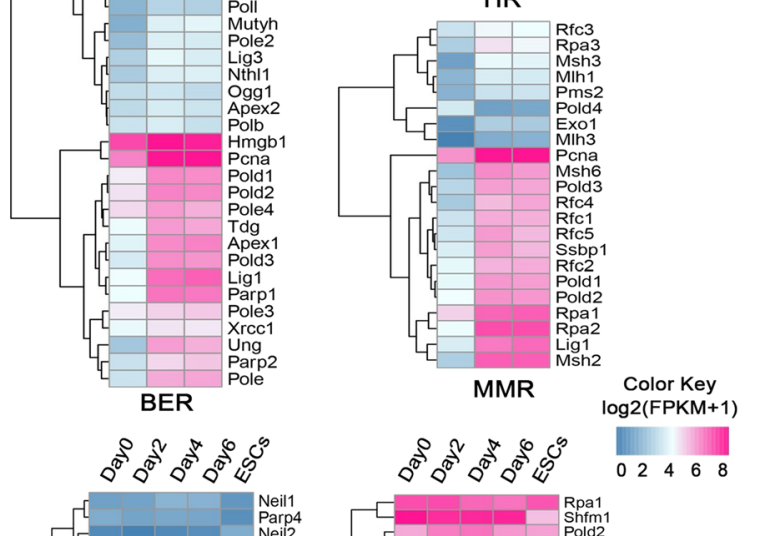
More DNA mutations in Iv-iPSCs than in other cell types after ionizing irradiation

We treated mouse lv-iPSCs, ESCs and MEFs with 4 Gy ionizing radiation to induce double-strand breaks. If not repaired properly, such breaks can result in genomic abnormalities, apoptosis and senescence [23, 26, 40]. Whole-genome DNA sequencing at $4 \mathrm{~h}$ after irradiation revealed more SNVs in lv-iPSCs than in the other cell types (Fig. 2a, Table 1), as well as more short indels (Fig. 2a, Table 2). MEFs showed a larger variety of copy number variations (CNVs) than the other cell types (Fig. 2a).

A larger number of SNVs and indels occurred in coding regions, intergenic regions, introns, $5^{\prime}$ untranslated regions (UTRs) and $3^{\prime}$ UTRs of lv-iPSCs than in other cell types (Fig. 2b, c). Irradiation was associated with the

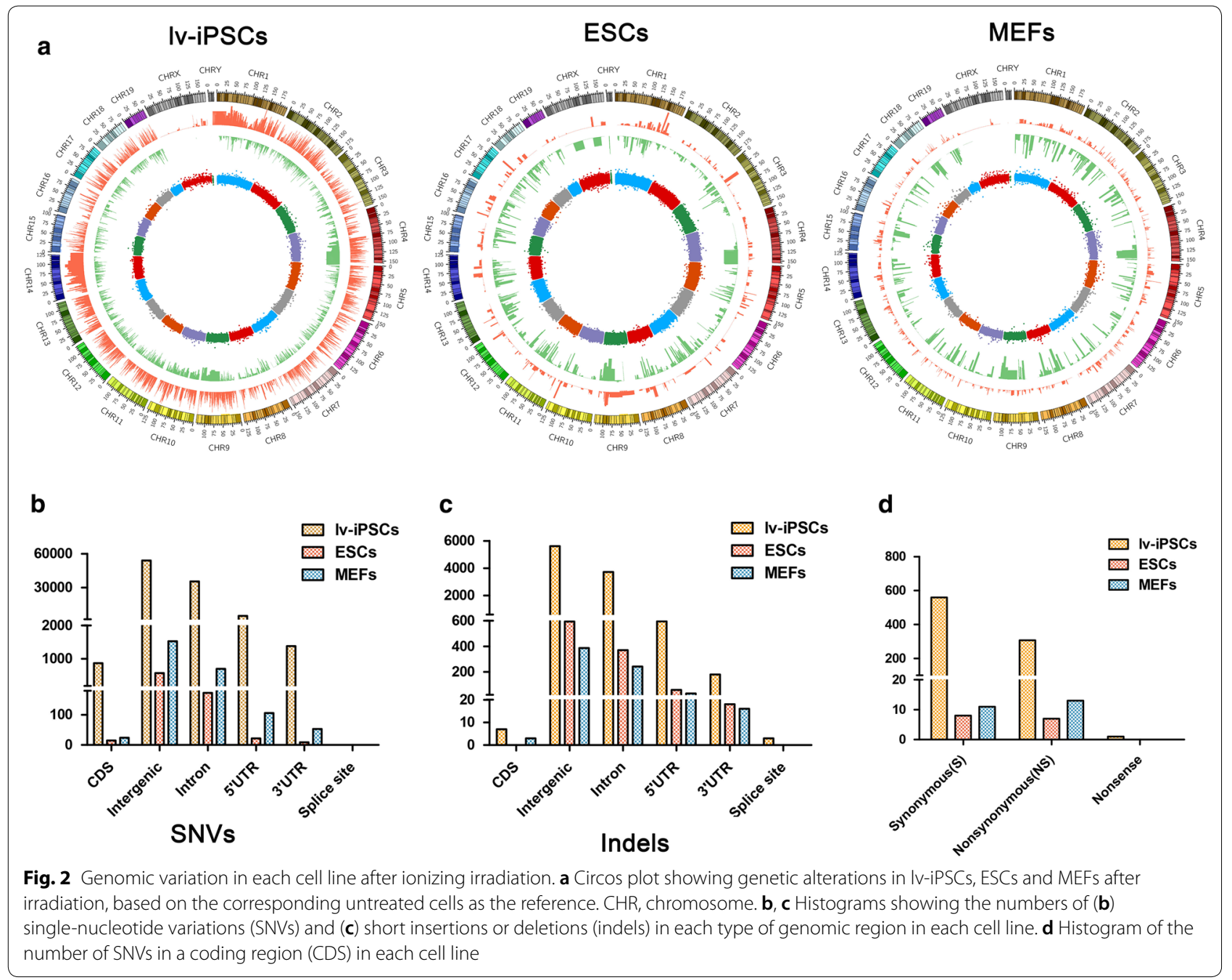

Table 1 Summary of sequencing results

\begin{tabular}{|c|c|c|c|c|c|c|}
\hline \multirow[t]{2}{*}{ Parameter } & \multicolumn{2}{|l|}{ Iv-iPSCs } & \multicolumn{2}{|l|}{ ESCs } & \multicolumn{2}{|l|}{ MEFs } \\
\hline & IR- & IR+ & IR- & IR+ & IR- & IR+ \\
\hline Total nucleotides sequenced (Gb) & 64.1 & 71.5 & 72.0 & 70.9 & 64.7 & 70.1 \\
\hline Genome coverage (fold) & $20 \times$ & $21 \times$ & $22 \times$ & $23 \times$ & $20 \times$ & $21 \times$ \\
\hline Total number of reads & $634,852,868$ & $708,065,514$ & $765,056,092$ & $754,255,820$ & $640,447,936$ & $693,376,402$ \\
\hline
\end{tabular}

ESCs mouse embryonic stem cells, IR ionizing radiation, $I v$-iPSCs lentivirus induced iPS cells, MEFs mouse embryonic fibroblasts 
Table 2 Summary of somatic indels in each cell line

\begin{tabular}{lrrr}
\hline & Iv-iPSCs & ESCs & MEFs \\
\hline Somatic indels & 10,127 & 1041 & 679 \\
CDS & 7 & 0 & 3 \\
Intergenic & 5616 & 594 & 387 \\
Intron & 3725 & 370 & 242 \\
5' UTR & 596 & 59 & 31 \\
3' UTR & 180 & 18 & 16 \\
Splice site & 3 & 0 & 0
\end{tabular}

CDS coding sequence, indel insertion or deletion, UTR untranslated region

Table 3 Summary of somatic mutations in each cell line

\begin{tabular}{lrrr}
\hline & Iv-iPSCs & ESCs & MEFs \\
\hline Somatic mutation & 92,027 & 789 & 2403 \\
CDS & 867 & 15 & 24 \\
Intergenic & 54,086 & 570 & 1526 \\
Intron & 35,567 & 173 & 694 \\
5' UTR & 5128 & 22 & 106 \\
3' UTR & 1379 & 9 & 53 \\
Splice site & 0 & 0 & 0 \\
CDS & 867 & 15 & 24 \\
Synonymous & 559 & 8 & 11 \\
Nonsynonymous & 307 & 7 & 13 \\
Nonsense & 1 & 0 & 0
\end{tabular}

CDS coding sequence, indel insertion or deletion, UTR untranslated region

appearance of many more synonymous point mutations in coding regions in lv-iPSCs (559) than in ESCs (8) or MEFs (11) (Fig. 2d, Table 3). Similarly, many more nonsynonymous point mutations in coding regions were found in lv-iPSCs (307) than in ESCs (7) or MEFs (13) (Fig. 2d, Tables 3, 4, 5, 6).

Similar gene expression profile in Iv-iPSCs with or without ionizing radiation

To determine whether ionizing radiation alters the expression of certain genes in lv-iPSCs that may help explain the high mutation rate, RNA-seq analysis was conducted in irradiated versus control cells. The results indicated a similar gene expression profile with or without radiation (Fig. 3a). In fact, irradiation appeared to upregulate only 46 genes in ESCs and 30 genes in lv-iPSCs (Fig. 3b). In contrast to the genes in lv-iPSCs that radiation up-regulated, majority of the genes up-regulated in ESCs is implicated in cellular response to stress and cell cycle processes (Fig. 3c, d).

Expression levels of genes involved in DNA damage repair pathways were higher in lv-iPSCs and ESCs than in MEFs, and ionizing radiation did not substantially alter the expression of these genes (Fig. 3e). Thus the genomic instability of lv-iPSCs is unlikely to reflect changes in the expression level of genes involved in DNA damage repair.

\section{Weaker DNA damage repair response to ionizing radiation in Iv-iPSCs}

The phosphorylated histone variant $\mathrm{H} 2 \mathrm{AX}(\gamma-\mathrm{H} 2 \mathrm{AX})$ is a marker of double-strand breaks. Ionizing radiation significantly increased the number of $\gamma$-H2AX foci in lviPSCs, ESCs and MEFs, but the magnitude of decrease was much smaller in lv-iPSCs (Fig. 4a), suggesting lower capacity to repair DNA damage.

Next we tested whether the lower genomic stability of lv-iPSCs reflects deficiency in the error-free HR repair pathway. Indeed, we found ATM phosphorylation to be defective in lv-iPSCs (Fig. 4b) [30, 41]. We also found lower levels of $\mathrm{H} 3 \mathrm{~K} 9 \mathrm{me} 3$, which recruits repair proteins to double-strand breaks, in irradiated lv-iPSCs than in irradiated ESCs or MEFs (Fig. 4c). All together, these findings may help explain the higher mutation rate of lv-iPSCs.

Lower genomic stability in Iv-iPSCs than ci-iPSCs

Treatment with ionizing radiation led to higher levels of phosphorylated ATM in ci-iPSCs than in lv-iPSCs (Fig. 5a). This may help explain the higher genomic stability of ci-iPSCs [41]. Whole-genome re-sequencing at $4 \mathrm{~h}$ after irradiation revealed 1709 SNVs in the ci-iPSCs;

Table 4 Frequencies of coding SNVs in ESCs exposed to ionizing radiation

\begin{tabular}{|c|c|c|c|c|c|c|}
\hline$\#$ & Locus & Gene & Mutation & Amino acid change & Freq. IR- (\%) & Freq. IR+ (\%) \\
\hline 1 & Chr1:46244148 & Dnahc7b & $\mathrm{T}->\mathrm{C}$ & $V->A$ & 0.0 & 28.57 \\
\hline 2 & Chr1:172987924 & Fcgr3 & $A->C$ & $S->A$ & 0.0 & 30 \\
\hline 3 & Chr2:180330052 & Ogfr & $A->G$ & $E->G$ & 0.0 & 22.06 \\
\hline 4 & Chr8:22465823 & Defa-rs1 & $C->G$ & $R->P$ & 0.0 & 20 \\
\hline 5 & Chr10:80640826 & Eef2 & $G->A$ & $E->K$ & 0.0 & 30.11 \\
\hline 6 & Chr15:77465439 & Apol11b & $C->A$ & $\mathrm{~K}->\mathrm{N}$ & 0.0 & 20 \\
\hline 7 & chrX:131293286 & Armcx3 & $G->A$ & $C->Y$ & 0.0 & 21.62 \\
\hline
\end{tabular}

$I R$ - control cells not irradiated, $I R+$ irradiated cells, SNV single-nucleotide variants 
Table 5 Frequencies of coding SNVs in MEFs exposed to ionizing radiation

\begin{tabular}{|c|c|c|c|c|c|c|}
\hline$\#$ & Locus & Gene & Mutation & $\begin{array}{l}\text { Amino acid } \\
\text { change }\end{array}$ & Freq. IR- (\%) & Freq. IR+ (\%) \\
\hline 1 & Chr1:174406441 & Slamf9 & $\mathrm{T}->\mathrm{C}$ & $M->T$ & 0.0 & 23.68 \\
\hline 2 & Chr2:10014034 & Kin & $G->A$ & $E->K$ & 0.0 & 20.00 \\
\hline 3 & Chr4:120619977 & Zfp69 & $A->G$ & $S->P$ & 0.0 & 20.00 \\
\hline 4 & Chr4:146162835 & Zfp600 & $\mathrm{T}->\mathrm{A}$ & $I->K$ & 0.0 & 20.00 \\
\hline 5 & Chr5:72655729 & Atp10d & $C \rightarrow \mathrm{G}$ & $P->R$ & 0.0 & 27.78 \\
\hline 6 & Chr7:25371714 & Zfp575 & $\mathrm{G}->\mathrm{A}$ & $A->V$ & 0.0 & 25.00 \\
\hline 7 & Chr7:31658366 & $\mathrm{Cd} 22$ & $C->T$ & $R->Q$ & 0.0 & 30.56 \\
\hline 8 & Chr7:48249435 & 4930433l11Rik & $A \rightarrow T$ & $D->V$ & 0.0 & 23.08 \\
\hline 9 & Chr7:48249440 & 4930433I11Rik & $G->C$ & $A->P$ & 0.0 & 24.00 \\
\hline 10 & Chr8:93611040 & $\mathrm{Rbl2}$ & $\mathrm{G} \rightarrow>C$ & $\mathrm{R}->\mathrm{T}$ & 0.0 & 20.83 \\
\hline 11 & Chr14:52076074 & Vmn2r89 & $C->T$ & $A->V$ & 0.0 & 20.00 \\
\hline 12 & Chr18:67019622 & Mc4r & $C \rightarrow>T$ & $G \rightarrow>S$ & 0.0 & 22.50 \\
\hline 13 & Chr18:70668975 & Poli & $C \rightarrow T$ & $G->R$ & 0.0 & 29.03 \\
\hline
\end{tabular}

$I R-$ control cells not irradiated, $I R+$ irradiated cells, SNV single-nucleotide variants

this was slightly more than in treated ESCs but far less than in lv-iPSCs (Fig. 5b). Similarly, the proportion of SNVs in coding sequences, introns, $5^{\prime}$ or $3^{\prime}$ UTRs and intergenic regions was slightly higher in ci-iPSCs than in ESCs, but much higher in lv-iPSCs (Fig. 5c, d). These results indicate greater genomic stability in ci-iPSCs than in lv-iPSCs, which is due at least in part to greater activity of the HR pathway of DNA damage repair.

\section{Iv-iPSCs can tolerate more genomic DNA variation}

The abovementioned results led us to hypothesize that lv-iPSCs can survive with greater genomic variation than the other cell types. Consistent with this hypothesis, we found that lv-iPSCs indeed had more DNA variation than the other cell types, yet the percentage of apoptotic lv-iPSCs did not increase between 24 and $48 \mathrm{~h}$ after irradiation (Fig. 6a) and the rate of lv-iPSC proliferation was greater than that of ESCs or MEFs (Fig. 6b). When we analyzed whether irradiation arrested lv-iPSCs in the G2/M phase, we observed a high proportion of arrested cells at $24 \mathrm{~h}$ after irradiation, but a lower proportion at $48 \mathrm{~h}$ (Fig. 6c). We observed similar results with ESCs, showing an increased proportion of ESCs in G2/M phase at $24 \mathrm{~h}$ after irradiation and a lower radiation arrest at $48 \mathrm{~h}$. These results suggest that lv-iPSCs tolerate greater genomic DNA variation than the other cell types.

\section{Iv-iPSCs are more susceptible to DNA damage}

Next we compared genomic stability in mice derived from lv-iPSCs versus ESCs. C57 mice were included as additional control. Irradiation of the mice led to a higher percentage of impaired bone marrow cells (Fig. 7a-c) and of tail DNA in bone marrow cells (Fig. 7d) in iPSCderived mice than in ESC-derived mice and C57 mice. These results suggest that mice derived from lv-iPSCs have lower DNA damage repair capability than ESCderived or C57 mice and are therefore more susceptible to DNA damage.

Taken together, our in vitro and in vivo experiments suggest that lv-iPSCs are more sensitive to environmental stress than ci-iPSCs, ESCs or MEFs. Ionizing radiation induces higher genomic mutation rates in lv-iPSCs, which nevertheless better tolerate the resulting genomic alterations. Genomic mutations that accumulate in lviPSCs are passed onto the next generation, resulting in genomic instability (Fig. 8).

\section{Discussion}

Reprogramming to generate iPSCs more efficiently [29, 42-51] has been linked to the accumulation of genomic abnormalities [52-59]. This poses a problem for the use of iPSCs, since mice derived from such cells can tolerate the accumulation of somatic mutations for up to six generations [60]. In the present study, we used wholegenome sequencing to compare the genomic stability of iPSCs prepared using lentivirus or chemically, and to benchmark that stability against ESCs and MEFs. We found that ionizing irradiation led to the highest rate of somatic mutations and short indels in lv-iPSCs, and this correlated with low levels of ATM phosphorylation, 
Table 6 Frequencies of coding SNVs in Iv-iPSCs exposed to ionizing radiation

\begin{tabular}{|c|c|c|c|c|c|c|}
\hline \# & Locus & Gene & Mutation & $\begin{array}{l}\text { Amino acid } \\
\text { change }\end{array}$ & Freq. IR- (\%) & Freq. IR+ (\%) \\
\hline 1 & chr1:30861639 & Phf3 & $C->G$ & $E->Q$ & 0.00 & 20.93 \\
\hline 2 & chr1:60166069 & Carf & $C->T$ & $\mathrm{R}->\mathrm{W}$ & 0.00 & 42.86 \\
\hline 3 & chr1:92665043 & Col6a3 & $C->G$ & $E->D$ & 0.00 & 22.73 \\
\hline 4 & chr1:108649819 & Kdsr & $G \rightarrow>$ & $D->E$ & 0.00 & 27.59 \\
\hline 5 & chr1:152550404 & Hmcn 1 & $C->T$ & $V->1$ & 0.00 & 25.00 \\
\hline 6 & chr1:166275528 & Nme7 & $\mathrm{G}->\mathrm{A}$ & $G \rightarrow S$ & 0.00 & 32.26 \\
\hline 7 & chr1:171863885 & 1700084C01Rik & $\mathrm{G} \rightarrow>\mathrm{A}$ & $\mathrm{G}->S$ & 0.00 & 25.00 \\
\hline 8 & chr1:175866740 & Ifi203 & $G->A$ & $\mathrm{~T}->\mathrm{M}$ & 0.00 & 28.57 \\
\hline 9 & chr1:186630980 & Mosc1 & $G \rightarrow C$ & $D->E$ & 0.00 & 23.08 \\
\hline 10 & chr1:186740013 & Mark1 & $\mathrm{T}->\mathrm{A}$ & $E->D$ & 0.00 & 32.14 \\
\hline 11 & chr2:10112008 & Itih5 & $\mathrm{T}->\mathrm{C}$ & $S->P$ & 0.00 & 42.31 \\
\hline 12 & chr2:31655794 & Abl1 & $A->G$ & $S->G$ & 0.00 & 25.00 \\
\hline 13 & chr2:31656413 & Abl1 & $A->C$ & $\mathrm{~N} \rightarrow>\mathrm{T}$ & 0.00 & 24.24 \\
\hline 14 & chr2:34634942 & Rabepk & $\mathrm{T} \rightarrow \mathrm{C}$ & $K->E$ & 0.00 & 44.44 \\
\hline 15 & chr2:34858984 & $\mathrm{Hc}$ & $C \rightarrow>T$ & $\mathrm{~S}->\mathrm{N}$ & 0.00 & 20.51 \\
\hline 16 & chr2:79182476 & Cerkl & $C \rightarrow T$ & $A->T$ & 0.00 & 24.00 \\
\hline 17 & chr2:86000090 & Olfr1042 & $\mathrm{T} \rightarrow \mathrm{C}$ & $\mathrm{T}->\mathrm{A}$ & 0.00 & 42.86 \\
\hline 18 & chr2:86154881 & Olfr1053 & $A->C$ & $1->M$ & 0.00 & 42.86 \\
\hline 19 & chr2:86828637 & Olfr1 101 & $\mathrm{~T}->\mathrm{G}$ & $Q \rightarrow P$ & 0.00 & 41.67 \\
\hline 20 & chr2:87149857 & Olfr1118 & $A->G$ & $K->E$ & 0.00 & 40.74 \\
\hline 21 & chr2:89033480 & Olfr1226 & $\mathrm{G} \rightarrow>\mathrm{A}$ & $S->F$ & 0.00 & 57.14 \\
\hline 22 & chr2:90749357 & Kbtbd4 & $A->G$ & $I->V$ & 0.00 & 36.36 \\
\hline 23 & chr2:90894429 & Psmc3 & $A->G$ & $\mathrm{~T} \rightarrow>\mathrm{A}$ & 0.00 & 23.53 \\
\hline 24 & chr2:91757766 & Ambra1 & $G \rightarrow A$ & $\mathrm{R}->\mathrm{Q}$ & 0.00 & 60.71 \\
\hline 25 & chr2:92815310 & Prdm11 & $G \rightarrow A$ & $S->L$ & 0.00 & 43.33 \\
\hline 26 & chr2:119346136 & Exd1 & $\mathrm{T}->\mathrm{A}$ & $H->L$ & 0.00 & 35.00 \\
\hline 27 & chr2:119577973 & Ltk & $C->T$ & $G \rightarrow>E$ & 0.00 & 34.38 \\
\hline 28 & chr2:120104674 & Pla2g4d & $G->A$ & $P->L$ & 0.00 & 20.00 \\
\hline 29 & chr2:120265164 & Ganc & $C \rightarrow \mathrm{G}$ & $1->M$ & 0.00 & 40.00 \\
\hline 30 & chr2:120357660 & Zfp106 & $G->T$ & $\mathrm{Q}->\mathrm{K}$ & 0.00 & 42.31 \\
\hline 31 & chr2:126412071 & Slc27a2 & $G->T$ & $A \rightarrow>S$ & 0.00 & 24.00 \\
\hline 32 & chr2:127182455 & Astl & $C \rightarrow>T$ & $P->L$ & 0.00 & 30.56 \\
\hline 33 & chr2:127267842 & Fahd2a & $C->A$ & $G->W$ & 0.00 & 21.74 \\
\hline 34 & chr2:146172498 & Ralgapa2 & $C \rightarrow>T$ & $V->1$ & 0.00 & 25.00 \\
\hline 35 & chr2:150299134 & Zfp345 & $A \rightarrow>T$ & $L \rightarrow Q$ & 0.00 & 24.00 \\
\hline 36 & chr2:153757199 & Bpifb3 & $G->A$ & $M->1$ & 0.00 & 33.33 \\
\hline 37 & chr2:157822874 & Tti1 & $\mathrm{T} \rightarrow \mathrm{C}$ & $K->R$ & 0.00 & 20.59 \\
\hline 38 & chr2:157832871 & Tti1 & $C->T$ & $\mathrm{~S}->\mathrm{N}$ & 0.00 & 21.74 \\
\hline 39 & chr2:165177990 & Zfp663 & $C \rightarrow>T$ & $\mathrm{R}->\mathrm{Q}$ & 0.00 & 21.74 \\
\hline 40 & chr2:165880571 & Ncoa3 & $G->A$ & $\mathrm{~S}->\mathrm{N}$ & 0.00 & 43.48 \\
\hline 41 & chr2:174471852 & Zfp831 & $\mathrm{T}->\mathrm{C}$ & $S->P$ & 0.00 & 25.93 \\
\hline 42 & chr3:19570978 & Trim55 & $G \rightarrow A$ & $G \rightarrow S$ & 0.00 & 29.17 \\
\hline 43 & chr3:20127155 & Cpa3 & $\mathrm{T}->\mathrm{A}$ & $K->1$ & 0.00 & 36.36 \\
\hline 44 & chr3:65861245 & Veph1 & $A->G$ & $S->P$ & 0.00 & 25.00 \\
\hline 45 & chr3:88240586 & Sema4a & $G->A$ & $A \rightarrow>V$ & 0.00 & 29.41 \\
\hline 46 & chr3:94167523 & $C 2 c d 4 d$ & $G->C$ & $R->P$ & 0.00 & 22.22 \\
\hline 47 & chr3:96096266 & Fcgr1 & $G->A$ & $P \rightarrow S$ & 0.00 & 20.00 \\
\hline 48 & chr3:97414088 & Chd1I & $\mathrm{T}->\mathrm{C}$ & $S->G$ & 0.00 & 42.86 \\
\hline 49 & chr3:105789443 & Ovgp1 & $C \rightarrow>T$ & $\mathrm{~T}->\mid$ & 0.00 & 21.74 \\
\hline
\end{tabular}


Table 6 (continued)

\begin{tabular}{|c|c|c|c|c|c|c|}
\hline$\#$ & Locus & Gene & Mutation & $\begin{array}{l}\text { Amino acid } \\
\text { change }\end{array}$ & Freq. IR- (\%) & Freq. IR+ (\%) \\
\hline 50 & chr3:116192199 & Rtcd 1 & $C->T$ & $V->1$ & 0.00 & 27.27 \\
\hline 51 & chr3:118377426 & Dpyd & $\mathrm{G}->\mathrm{A}$ & $\mathrm{S}->\mathrm{N}$ & 0.00 & 41.67 \\
\hline 52 & chr3:137770265 & Mttp & $\mathrm{T}->\mathrm{A}$ & $\mathrm{T} \rightarrow>\mathrm{S}$ & 0.00 & 26.09 \\
\hline 53 & chr3:142271248 & Gbp1 & $G \rightarrow>A$ & $E->K$ & 0.00 & 30.95 \\
\hline 54 & chr4:57660898 & Palm2 & $G \rightarrow>A$ & $V->1$ & 0.00 & 40.00 \\
\hline 55 & chr4:106415886 & Fam151a & $G \rightarrow>A$ & $\mathrm{R}->\mathrm{Q}$ & 0.00 & 51.85 \\
\hline 56 & chr4:116265516 & Gpbp111 & $\mathrm{T}->\mathrm{A}$ & $S->T$ & 0.00 & 25.00 \\
\hline 57 & chr4:118154980 & Tie1 & $\mathrm{T}->\mathrm{C}$ & $D->G$ & 0.00 & 30.30 \\
\hline 58 & chr4:119804939 & Hivep3 & $\mathrm{T}->\mathrm{C}$ & $L->P$ & 0.00 & 25.00 \\
\hline 59 & chr4:120620061 & Zfp69 & $\mathrm{T}->\mathrm{C}$ & $\mathrm{T}->\mathrm{A}$ & 0.00 & 40.00 \\
\hline 60 & chr4:120620067 & Zfp69 & $\mathrm{T}->\mathrm{G}$ & $\mathrm{T}->\mathrm{P}$ & 0.00 & 37.04 \\
\hline 61 & chr4:136193988 & Lactbl1 & $A \rightarrow G$ & $S->G$ & 0.00 & 33.33 \\
\hline 62 & chr4:141674086 & Kazn & $C->T$ & $A \rightarrow>T$ & 0.00 & 20.00 \\
\hline 63 & chr4:147839151 & Mtor & $C \rightarrow T$ & $\mathrm{R}->\mathrm{C}$ & 0.00 & 25.71 \\
\hline 64 & chr5:23825901 & Kenh2 & $T->G$ & $T->P$ & 0.00 & 34.78 \\
\hline 65 & chr5:23905831 & Abcb8 & $\mathrm{T}->\mathrm{C}$ & $W->R$ & 0.00 & 20.00 \\
\hline 66 & chr5:64289838 & 0610040J01Rik & $\mathrm{T}->\mathrm{A}$ & $L->Q$ & 0.00 & 24.00 \\
\hline 67 & chr5:90672580 & Ankrd17 & $A->G$ & ${ }^{*}->Q$ & 0.00 & 28.89 \\
\hline 68 & chr5:109231028 & Vmn2r8 & $\mathrm{T}->\mathrm{C}$ & $E->G$ & 0.00 & 20.83 \\
\hline 69 & chr5:122789758 & Rad9b & $A->G$ & $L->S$ & 0.00 & 37.93 \\
\hline 70 & chr5:138473740 & Smok3a & $A->G$ & $\mathrm{Q}->\mathrm{R}$ & 0.00 & 32.00 \\
\hline 71 & chr5:142948192 & C330006K01Rik & $\mathrm{G}->\mathrm{A}$ & $\mathrm{G} \rightarrow>\mathrm{R}$ & 0.00 & 22.86 \\
\hline 72 & chr5:146996767 & 1700001J03Rik & $C->T$ & $\mathrm{R}->\mathrm{H}$ & 0.00 & 30.56 \\
\hline 73 & chr6:67242225 & $1112 \mathrm{rb} 2$ & $\mathrm{~T}->\mathrm{C}$ & $Y \rightarrow C$ & 0.00 & 21.21 \\
\hline 74 & chr6:67423944 & $\| 23 r$ & $\mathrm{~T}->\mathrm{C}$ & $\mathrm{T}->\mathrm{A}$ & 0.00 & 26.09 \\
\hline 75 & chr6:72529697 & Elmod3 & $\mathrm{T}->\mathrm{C}$ & $\mathrm{H}->\mathrm{R}$ & 0.00 & 25.00 \\
\hline 76 & chr6:123355291 & Vmn2r20 & $G->A$ & $A \rightarrow>V$ & 0.00 & 24.00 \\
\hline 77 & chr6:124820464 & $\mathrm{Cd} 4$ & $G->A$ & $P->S$ & 0.00 & 30.77 \\
\hline 78 & chr6:128334974 & 4933413G19Rik & $G->A$ & $G \rightarrow R$ & 0.00 & 23.53 \\
\hline 79 & chr6:129369539 & Clec9a & $A \rightarrow G$ & $\mathrm{~N}->\mathrm{S}$ & 0.00 & 40.91 \\
\hline 80 & chr6:132907129 & Tas2r131 & $C->T$ & $\mathrm{R}->\mathrm{Q}$ & 0.00 & 26.09 \\
\hline 81 & chr6:141942744 & Gm6614 & $C->T$ & $\mathrm{D}->\mathrm{N}$ & 0.00 & 32.14 \\
\hline 82 & chr6:142186044 & Slco1a5 & $G->A$ & $S->L$ & 0.00 & 25.00 \\
\hline 83 & chr6:142186083 & Slco1a5 & $\mathrm{G}->\mathrm{T}$ & $\mathrm{P}->\mathrm{H}$ & 0.00 & 27.27 \\
\hline 84 & chr6:142201619 & Slco1a5 & $\mathrm{T}->\mathrm{G}$ & $D->A$ & 0.00 & 35.29 \\
\hline 85 & chr6:142251831 & lapp & $G \rightarrow C$ & $S->T$ & 0.00 & 26.92 \\
\hline 86 & chr7:3794286 & Pira2 & $A->G$ & $S->P$ & 0.00 & 26.09 \\
\hline 87 & chr7:7278011 & Vmn2r30 & $\mathrm{T}->\mathrm{A}$ & $\mathrm{N}->1$ & 0.00 & 22.22 \\
\hline 88 & chr7:10859910 & Vmn1r66 & $G \rightarrow>A$ & $\mathrm{H}->\mathrm{Y}$ & 0.00 & 38.10 \\
\hline 89 & chr7:11333654 & Vmn1r71 & $G \rightarrow A$ & $\mathrm{~T}->1$ & 0.00 & 50.00 \\
\hline 90 & chr7:12738597 & Vmn1r78 & $\mathrm{T}->\mathrm{C}$ & $\mathrm{F} \rightarrow>\mathrm{S}$ & 0.00 & 20.00 \\
\hline 91 & chr7:17743709 & Ceacam3 & $C->G$ & $L->V$ & 0.00 & 20.00 \\
\hline 92 & chr7:17743712 & Ceacam3 & $A \rightarrow C$ & $\mid->L$ & 0.00 & 22.50 \\
\hline 93 & chr7:18337478 & Ceacam5 & $G \rightarrow A$ & $\mathrm{R}->\mathrm{Q}$ & 0.00 & 22.73 \\
\hline 94 & chr7:18662759 & Ceacam 12 & $G->C$ & $G->A$ & 0.00 & 26.09 \\
\hline 95 & chr7:19672969 & Dmpk & $G->A$ & $A \rightarrow T$ & 0.00 & 33.33 \\
\hline 96 & chr7:26134047 & Megf8 & $C->T$ & $\mathrm{H}->\mathrm{Y}$ & 0.00 & 20.45 \\
\hline 97 & chr7:26261696 & Ceacam1 & $C->G$ & $A->P$ & 0.00 & 20.00 \\
\hline 98 & chr7:29779122 & Map4k1 & $\mathrm{T}->\mathrm{C}$ & $C->R$ & 0.00 & 21.05 \\
\hline
\end{tabular}


Table 6 (continued)

\begin{tabular}{|c|c|c|c|c|c|c|}
\hline$\#$ & Locus & Gene & Mutation & $\begin{array}{l}\text { Amino acid } \\
\text { change }\end{array}$ & Freq. IR- (\%) & Freq. IR+ (\%) \\
\hline 99 & chr7:31370138 & Wbp7 & $C->A$ & $A \rightarrow S$ & 0.00 & 31.82 \\
\hline 100 & chr7:31374957 & Zbtb32 & $C->T$ & $A \rightarrow>T$ & 0.00 & 30.77 \\
\hline 101 & chr7:31391976 & Upk1a & $G->A$ & $T->1$ & 0.00 & 31.03 \\
\hline 102 & chr7:31696435 & Mag & $C->T$ & $V->1$ & 0.00 & 40.00 \\
\hline 103 & chr7:48299575 & Gm4884 & $G \rightarrow T$ & $A \rightarrow S$ & 0.00 & 21.28 \\
\hline 104 & chr7:48299666 & Gm4884 & $A \rightarrow C$ & $\mathrm{H} \rightarrow>\mathrm{P}$ & 0.00 & 22.22 \\
\hline 105 & chr7:51608348 & Shank1 & $G \rightarrow A$ & $G \rightarrow>S$ & 0.00 & 20.00 \\
\hline 106 & chr7:54720024 & Mrgpra2b & $\mathrm{T}->\mathrm{A}$ & $H->L$ & 0.00 & 42.42 \\
\hline 107 & chr7:55424237 & Mrgprb5 & $A->G$ & $1->T$ & 0.00 & 30.43 \\
\hline 108 & chr7:55424238 & Mrgprb5 & $\mathrm{T}->\mathrm{A}$ & $\mathrm{I}->\mathrm{F}$ & 0.00 & 29.17 \\
\hline 109 & chr7:86855301 & Kif7 & $C->T$ & $\mathrm{R}->\mathrm{H}$ & 0.00 & 42.42 \\
\hline 110 & chr7:89455314 & Sh3gl3 & $\mathrm{T}->\mathrm{G}$ & $S->A$ & 0.00 & 40.00 \\
\hline 111 & chr7:108978612 & Inppl1 & $\mathrm{G}->\mathrm{A}$ & $\mathrm{H}->\mathrm{Y}$ & 0.00 & 35.29 \\
\hline 112 & chr7:109584206 & Stim1 & $\mathrm{T}->\mathrm{A}$ & $\mathrm{L}->\mathrm{H}$ & 0.00 & 24.14 \\
\hline 113 & chr7:109762976 & Olfr553 & $G \rightarrow>T$ & $L->M$ & 0.00 & 23.26 \\
\hline 114 & chr7:109832588 & Trim68 & $\mathrm{T}->\mathrm{C}$ & $I->V$ & 0.00 & 32.00 \\
\hline 115 & chr7:109862636 & Olfr33 & $A->G$ & $\mathrm{~F} \rightarrow>\mathrm{S}$ & 0.00 & 27.78 \\
\hline 116 & chr7:109872941 & Olfr559 & $A->T$ & $1->N$ & 0.00 & 23.53 \\
\hline 117 & chr7:110121916 & Olfr577 & $C \rightarrow T$ & $A \rightarrow>T$ & 0.00 & 34.48 \\
\hline 118 & chr7:110234973 & Olfr584 & $\mathrm{T}->\mathrm{C}$ & $F->L$ & 0.00 & 22.58 \\
\hline 119 & chr7:110336027 & Olfr592 & $A->G$ & $\mathrm{H}->\mathrm{R}$ & 0.00 & 33.33 \\
\hline 120 & chr7:110399181 & Dub2a & $C->G$ & $E->Q$ & 0.00 & 42.31 \\
\hline 121 & chr7:110566860 & Usp1715 & $C->A$ & $P \rightarrow>T$ & 0.00 & 25.00 \\
\hline 122 & chr7:111161069 & Olfr639 & $A->G$ & $1->T$ & 0.00 & 25.71 \\
\hline 123 & chr7:111161070 & Olfr639 & $\mathrm{T}->\mathrm{C}$ & $I->V$ & 0.00 & 27.78 \\
\hline 124 & chr7:111297423 & Ubqlnl & $C \rightarrow G$ & $\mathrm{Q}->\mathrm{H}$ & 0.00 & 23.33 \\
\hline 125 & chr7:111298754 & Ubqlnl & $\mathrm{T}->\mathrm{G}$ & $T->P$ & 0.00 & 31.58 \\
\hline 126 & chr7:111302579 & E030002O03Rik & $A \rightarrow G$ & $V->A$ & 0.00 & 20.00 \\
\hline 127 & chr7:111560797 & Trim30a & $\mathrm{G}->C$ & $T \rightarrow>S$ & 0.00 & 33.33 \\
\hline 128 & chr7:111793632 & Olfr658 & $\mathrm{T}->\mathrm{C}$ & $\mathrm{T}->\mathrm{A}$ & 0.00 & 25.00 \\
\hline 129 & chr7:112009277 & Dub1 & $C->T$ & $\mathrm{R}->\mathrm{C}$ & 0.00 & 35.00 \\
\hline 130 & chr7:112041695 & Olfr666 & $G->A$ & $A->V$ & 0.00 & 29.03 \\
\hline 131 & chr7:112123974 & Olfr671 & $C \rightarrow A$ & $S->1$ & 0.00 & 20.00 \\
\hline 132 & chr7:112462829 & Olfr689 & $\mathrm{G}->\mathrm{T}$ & $A \rightarrow S$ & 0.00 & 21.95 \\
\hline 133 & chr7:112708033 & Apbb1 & $\mathrm{G}->\mathrm{A}$ & $S->F$ & 0.00 & 26.32 \\
\hline 134 & chr7:114029870 & Olfr706 & $\mathrm{G}->\mathrm{A}$ & $L->F$ & 0.00 & 23.08 \\
\hline 135 & chr7:114218082 & Olfr714 & $\mathrm{G} \rightarrow>\mathrm{A}$ & $V->1$ & 0.00 & 21.43 \\
\hline 136 & chr7:115302565 & Olfr485 & $C->T$ & $\mathrm{G}->\mathrm{E}$ & 0.00 & 28.00 \\
\hline 137 & chr7:115399125 & Olfr488 & $\mathrm{T}->\mathrm{C}$ & $\mathrm{K}->\mathrm{E}$ & 0.00 & 25.00 \\
\hline 138 & chr7:115968770 & Olfr514 & $\mathrm{T}->\mathrm{C}$ & $\mathrm{T}->\mathrm{A}$ & 0.00 & 25.00 \\
\hline 139 & chr7:116859980 & BC051019 & $\mathrm{G}->\mathrm{A}$ & $T->1$ & 0.00 & 26.09 \\
\hline 140 & chr7:135022359 & Zfp646 & $C->G$ & $L->V$ & 0.00 & 23.68 \\
\hline 141 & chr7:135024297 & Zfp646 & $G \rightarrow A$ & $E->K$ & 0.00 & 20.83 \\
\hline 142 & chr7:135026037 & Zfp646 & $A->G$ & $S->G$ & 0.00 & 28.89 \\
\hline 143 & chr8:4213992 & BC068157 & $G->A$ & $P->L$ & 0.00 & 52.38 \\
\hline 144 & chr8:80770162 & Ttc29 & $C->T$ & $P->L$ & 0.00 & 22.86 \\
\hline 145 & chr8:86691455 & 4930432K21Rik & $C->A$ & $P->T$ & 0.00 & 37.50 \\
\hline 146 & chr8:112256157 & Atxn1l & $C->G$ & $V->L$ & 0.00 & 21.88 \\
\hline 147 & chr9:21085574 & Kri1 & $\mathrm{T}->\mathrm{C}$ & $K->E$ & 0.00 & 35.71 \\
\hline
\end{tabular}


Table 6 (continued)

\begin{tabular}{|c|c|c|c|c|c|c|}
\hline$\#$ & Locus & Gene & Mutation & $\begin{array}{l}\text { Amino acid } \\
\text { change }\end{array}$ & Freq. IR- (\%) & Freq. IR+ (\%) \\
\hline 148 & chr9:21733911 & Ccdc159 & $\mathrm{G} \rightarrow>\mathrm{T}$ & $S->1$ & 0.00 & 51.72 \\
\hline 149 & chr9:22004013 & Zfp872 & $C->T$ & $L->F$ & 0.00 & 34.88 \\
\hline 150 & chr9:22005064 & Zfp872 & $G->A$ & $G->E$ & 0.00 & 34.15 \\
\hline 151 & chr9:22005066 & Zfp872 & $\mathrm{T}->\mathrm{C}$ & $*->R$ & 0.00 & 32.50 \\
\hline 152 & chr9:22058381 & Zfp599 & $C \rightarrow T$ & $M->1$ & 0.00 & 34.62 \\
\hline 153 & chr9:35646988 & 9230110F15Rik & $A \rightarrow G$ & $V \rightarrow>A$ & 0.00 & 22.22 \\
\hline 154 & chr9:36671150 & Fez1 & $A \rightarrow C$ & $E->D$ & 0.00 & 34.62 \\
\hline 155 & chr9:37869528 & Olfr885 & $G->A$ & $V->M$ & 0.00 & 27.27 \\
\hline 156 & chr9:41932183 & Sorl1 & $C->T$ & $S->N$ & 0.00 & 32.35 \\
\hline 157 & chr9:44073278 & Nlrx1 & $A \rightarrow C$ & $\mathrm{~F}->\mathrm{V}$ & 0.00 & 25.00 \\
\hline 158 & chr9:45557815 & Dscaml1 & $\mathrm{G} \rightarrow>C$ & $\mathrm{~K}->\mathrm{N}$ & 0.00 & 42.86 \\
\hline 159 & chr9:50490277 & Dixdc1 & $C \rightarrow>T$ & $\mathrm{R}->\mathrm{Q}$ & 0.00 & 21.74 \\
\hline 160 & chr9:55821819 & Rfpl3s & $G->A$ & $\mathrm{~T}->\mathrm{M}$ & 0.00 & 29.03 \\
\hline 161 & chr9:58347114 & 6030419C18Rik & $G \rightarrow A$ & $A \rightarrow T$ & 0.00 & 24.14 \\
\hline 162 & chr9:120873710 & Ulk4 & $\mathrm{T}->\mathrm{C}$ & $\mathrm{I}->\mathrm{V}$ & 0.00 & 23.68 \\
\hline 163 & chr10:18244674 & Nhsl1 & $G \rightarrow C$ & $C \rightarrow S$ & 0.00 & 21.88 \\
\hline 164 & chr10:18722769 & Tnfaip3 & $A \rightarrow G$ & $L->P$ & 0.00 & 28.00 \\
\hline 165 & chr10:51201543 & Gp49a & $C->T$ & $P->S$ & 0.00 & 22.22 \\
\hline 166 & chr10:51201551 & Gp49a & $\mathrm{T}->\mathrm{A}$ & $\mathrm{H} \rightarrow>\mathrm{Q}$ & 0.00 & 20.00 \\
\hline 167 & chr10:51203657 & Gp49a & $\mathrm{T}->\mathrm{C}$ & $\mathrm{Y}->\mathrm{H}$ & 0.00 & 27.50 \\
\hline 168 & chr10:51203677 & Gp49a & $\mathrm{T}->\mathrm{G}$ & $\mathrm{N}->\mathrm{K}$ & 0.00 & 44.74 \\
\hline 169 & chr10:53257912 & Mcm9 & $A \rightarrow T$ & $S->T$ & 0.00 & 37.50 \\
\hline 170 & chr10:61892173 & Supv311 & $C \rightarrow>T$ & $\mathrm{D}->\mathrm{N}$ & 0.00 & 31.43 \\
\hline 171 & chr10:62301871 & Tet1 & $\mathrm{T}->\mathrm{C}$ & $E->G$ & 0.00 & 27.59 \\
\hline 172 & chr10:62534718 & Pbld1 & $G \rightarrow T$ & $G \rightarrow>V$ & 0.00 & 26.67 \\
\hline 173 & chr10:62534721 & Pbld1 & $G \rightarrow A$ & $G \rightarrow>E$ & 0.00 & 26.67 \\
\hline 174 & chr10:69997479 & Fam13c & $\mathrm{T}->\mathrm{G}$ & $S->A$ & 0.00 & 23.68 \\
\hline 175 & chr10:82654374 & Chst11 & $G->A$ & $G \rightarrow S$ & 0.00 & 23.08 \\
\hline 176 & chr10:85391311 & $\mathrm{AsCl} 4$ & $G \rightarrow C$ & $G \rightarrow R$ & 0.00 & 28.57 \\
\hline 177 & chr10:99909744 & Tmtc3 & $C \rightarrow T$ & $\mathrm{R}->\mathrm{K}$ & 0.00 & 30.00 \\
\hline 178 & chr10:99914062 & Tmtc3 & $C \rightarrow T$ & $\mathrm{R}->\mathrm{K}$ & 0.00 & 44.83 \\
\hline 179 & chr10:100031465 & Cep290 & $A \rightarrow C$ & $M->L$ & 0.00 & 47.62 \\
\hline 180 & chr10:128448679 & Olfr763 & $\mathrm{T}->\mathrm{A}$ & $C \rightarrow S$ & 0.00 & 20.00 \\
\hline 181 & chr11:5587351 & Ankrd36 & $\mathrm{G}->\mathrm{A}$ & $V->1$ & 0.00 & 33.33 \\
\hline 182 & chr11:5587391 & Ankrd36 & $A \rightarrow T$ & $K->1$ & 0.00 & 22.22 \\
\hline 183 & chr11:6501551 & Nacad & $G \rightarrow>A$ & $P \rightarrow S$ & 0.00 & 39.39 \\
\hline 184 & chr11:23264045 & Usp34 & $A \rightarrow T$ & $E->D$ & 0.00 & 28.57 \\
\hline 185 & chr11:29429943 & Mtif2 & $A \rightarrow G$ & $\mathrm{Q}->\mathrm{R}$ & 0.00 & 25.93 \\
\hline 186 & chr11:29607190 & Rtn4 & $G \rightarrow C$ & $S->T$ & 0.00 & 25.00 \\
\hline 187 & chr11:29607841 & Rtn4 & $C->T$ & $A \rightarrow>V$ & 0.00 & 31.25 \\
\hline 188 & chr11:29646793 & Eml6 & $G \rightarrow C$ & $L->V$ & 0.00 & 37.14 \\
\hline 189 & chr11:32184064 & Hba-a1 & $G \rightarrow C$ & $G->A$ & 0.00 & 28.00 \\
\hline 190 & chr11:35622812 & Rars & $\mathrm{G} \rightarrow>\mathrm{T}$ & $A->E$ & 0.00 & 22.22 \\
\hline 191 & chr11:48988354 & Btnl9 & $\mathrm{T}->\mathrm{C}$ & $\mathrm{Q}->\mathrm{R}$ & 0.00 & 39.13 \\
\hline 192 & chr11:52216575 & 9530068E07Rik & $C \rightarrow>T$ & $A \rightarrow>V$ & 0.00 & 34.38 \\
\hline 193 & chr11:62078872 & Adora2b & $G \rightarrow A$ & $\mathrm{R}->\mathrm{H}$ & 0.00 & 25.71 \\
\hline 194 & chr11:67688822 & Usp43 & $\mathrm{T}->\mathrm{C}$ & $M->V$ & 0.00 & 24.00 \\
\hline 195 & chr11:69010998 & Alox8 & $A \rightarrow G$ & $V->A$ & 0.00 & 21.43 \\
\hline 196 & chr11:70584746 & Zfp3 & $C \rightarrow A$ & $P->T$ & 0.00 & 20.83 \\
\hline
\end{tabular}


Table 6 (continued)

\begin{tabular}{|c|c|c|c|c|c|c|}
\hline$\#$ & Locus & Gene & Mutation & $\begin{array}{l}\text { Amino acid } \\
\text { change }\end{array}$ & Freq. IR- (\%) & Freq. IR+ (\%) \\
\hline 197 & chr11:70995613 & Nlrp1b & $A \rightarrow T$ & $F->Y$ & 0.00 & 21.74 \\
\hline 198 & chr11:70995614 & Nlrp1b & $A \rightarrow G$ & $F->L$ & 0.00 & 23.81 \\
\hline 199 & chr11:70995616 & Nlrp1b & $A \rightarrow C$ & $I->R$ & 0.00 & 22.73 \\
\hline 200 & chr11:72984698 & P2rx5 & $C->T$ & $A->V$ & 0.00 & 25.00 \\
\hline 201 & chr11:96214596 & Hoxb2 & $G \rightarrow A$ & $E->K$ & 0.00 & 61.90 \\
\hline 202 & chr1 1:96772447 & Cdk5rap3 & $C->T$ & $V->1$ & 0.00 & 47.50 \\
\hline 203 & chr11:101045277 & Cntnap1 & $C \rightarrow T$ & $S->L$ & 0.00 & 31.25 \\
\hline 204 & chr11:102935952 & Plcd3 & $A->T$ & $D->E$ & 0.00 & 23.81 \\
\hline 205 & chr11:106174196 & Cd79b & $\mathrm{T}->\mathrm{C}$ & $M->V$ & 0.00 & 22.22 \\
\hline 206 & chr11:120146302 & Bahcc1 & $C->G$ & $T->S$ & 0.00 & 21.43 \\
\hline 207 & chr12:18521595 & 5730507C01Rik & $A->T$ & $\mathrm{~N}->\mathrm{Y}$ & 0.00 & 20.00 \\
\hline 208 & chr12:21271015 & Asap2 & $C \rightarrow T$ & $\mathrm{~T}->1$ & 0.00 & 21.43 \\
\hline 209 & chr12:21379212 & Adam17 & $A \rightarrow C$ & $S->A$ & 0.00 & 20.69 \\
\hline 210 & chr12:25723341 & Kidins220 & $\mathrm{G}->\mathrm{A}$ & $G \rightarrow S$ & 0.00 & 31.82 \\
\hline 211 & chr12:32005994 & Lamb1 & $\mathrm{T}->\mathrm{C}$ & $V->A$ & 0.00 & 25.00 \\
\hline 212 & chr12:65573550 & Fscb & $A->G$ & $S->P$ & 0.00 & 25.00 \\
\hline 213 & chr12:77031626 & Syne2 & $G->A$ & $\mathrm{R}->\mathrm{K}$ & 0.00 & 20.00 \\
\hline 214 & chr12:77088037 & Syne2 & $A->G$ & $\mathrm{H} \rightarrow>\mathrm{R}$ & 0.00 & 37.93 \\
\hline 215 & chr12:77701313 & Spnb1 & $\mathrm{G} \rightarrow \mathrm{C}$ & $D->E$ & 0.00 & 27.08 \\
\hline 216 & chr12:77713010 & Spnb1 & $A->T$ & $M->K$ & 0.00 & 26.47 \\
\hline 217 & chr12:80369378 & Zfyve26 & $\mathrm{T}->\mathrm{C}$ & $\mathrm{Q} \rightarrow>\mathrm{R}$ & 0.00 & 28.00 \\
\hline 218 & chr12:85333734 & Acot2 & $A->G$ & $T->A$ & 0.00 & 22.86 \\
\hline 219 & chr12:88947186 & Oog1 & $G->A$ & $E->K$ & 0.00 & 20.45 \\
\hline 220 & chr12:111906810 & 1700001K19Rik & $\mathrm{T}->\mathrm{G}$ & $\mathrm{Q}->\mathrm{P}$ & 0.00 & 29.82 \\
\hline 221 & chr13:6564252 & Pitrm1 & $C->A$ & $\mathrm{~T}->\mathrm{K}$ & 0.00 & 32.14 \\
\hline 222 & chr13:6604968 & Pfkp & $C \rightarrow T$ & $V->M$ & 0.00 & 34.48 \\
\hline 223 & chr13:8886000 & $\mid d i 1$ & $\mathrm{~T}->\mathrm{C}$ & $S->P$ & 0.00 & 22.58 \\
\hline 224 & chr13:8958551 & Idi2 & $A \rightarrow G$ & $E->G$ & 0.00 & 27.27 \\
\hline 225 & chr13:9150373 & Larp4b & $\mathrm{T}->\mathrm{C}$ & $L \rightarrow>S$ & 0.00 & 34.48 \\
\hline 226 & chr13:9688439 & Zmynd11 & $C->T$ & $\mathrm{~S}->\mathrm{N}$ & 0.00 & 33.33 \\
\hline 227 & chr13:14097474 & Tbce & $\mathrm{G}->\mathrm{A}$ & $A \rightarrow>V$ & 0.00 & 22.73 \\
\hline 228 & chr13:23126330 & Vmn1r214 & $G->A$ & $E->K$ & 0.00 & 42.86 \\
\hline 229 & chr13:23126981 & Vmn1r214 & $C \rightarrow A$ & $\mathrm{Q}->\mathrm{K}$ & 0.00 & 40.91 \\
\hline 230 & chr13:23309404 & Vmn1r221 & $C \rightarrow A$ & $L->\mid$ & 0.00 & 30.77 \\
\hline 231 & chr13:23309956 & Vmn1r221 & $C \rightarrow \mathrm{G}$ & $L->V$ & 0.00 & 25.93 \\
\hline 232 & chr13:23579753 & Btn2a2 & $T->A$ & $\mid->L$ & 0.00 & 34.62 \\
\hline 233 & chr13:23647236 & Hist1h1d & $C->T$ & $\mathrm{~T}->1$ & 0.00 & 37.50 \\
\hline 234 & chr13:23855668 & Hist1h1a & $C->T$ & $A->V$ & 0.00 & 29.63 \\
\hline 235 & chr13:25085054 & Mrs2 & $\mathrm{T}->\mathrm{C}$ & $\mathrm{T}->\mathrm{A}$ & 0.00 & 21.74 \\
\hline 236 & chr13:40238189 & Ofccl & $\mathrm{G}->\mathrm{A}$ & $P->S$ & 0.00 & 20.83 \\
\hline 237 & chr13:58445640 & Kif27 & $\mathrm{T}->\mathrm{A}$ & $\mid->L$ & 0.00 & 23.81 \\
\hline 238 & chr13:70874611 & Adamts16 & $C->T$ & $G \rightarrow S$ & 0.00 & 24.14 \\
\hline 239 & chr13:70877487 & Adamts16 & $\mathrm{G} \rightarrow>C$ & $\mathrm{Q}->\mathrm{E}$ & 0.00 & 20.59 \\
\hline 240 & chr13:81583863 & Gpr98 & $C->T$ & $E->K$ & 0.00 & 34.48 \\
\hline 241 & chr13:96284081 & $\mathrm{F} 2 \mathrm{rl} 1$ & $C->T$ & $V->1$ & 0.00 & 25.00 \\
\hline 242 & chr13:98737291 & Rgnef & $\mathrm{G}->\mathrm{C}$ & $A->G$ & 0.00 & 33.33 \\
\hline 243 & chr14:45342600 & Gm8267 & $A \rightarrow>T$ & $M->K$ & 0.00 & 28.00 \\
\hline 244 & chr14:50393514 & 3632451O06Rik & $A->G$ & $V \rightarrow>A$ & 0.00 & 24.44 \\
\hline 245 & chr14:51135131 & Olfr742 & $A->G$ & $\mathrm{~N} \rightarrow>\mathrm{S}$ & 0.00 & 25.81 \\
\hline
\end{tabular}


Table 6 (continued)

\begin{tabular}{|c|c|c|c|c|c|c|}
\hline$\#$ & Locus & Gene & Mutation & $\begin{array}{l}\text { Amino acid } \\
\text { change }\end{array}$ & Freq. IR- (\%) & Freq. IR+ (\%) \\
\hline 246 & chr14:55283622 & Acin1 & $\mathrm{T}->\mathrm{C}$ & $K->E$ & 0.00 & 43.18 \\
\hline 247 & chr14:70175997 & Tnfrsf10b & $C->G$ & $P \rightarrow A$ & 0.00 & 27.78 \\
\hline 248 & chr14:70176001 & Tnfrsf10b & $\mathrm{T}->\mathrm{C}$ & $V->A$ & 0.00 & 25.00 \\
\hline 249 & chr14:78484964 & AU021034 & $A->G$ & $C->R$ & 0.00 & 22.22 \\
\hline 250 & chr15:41697429 & Abra & $\mathrm{G} \rightarrow \mathrm{C}$ & $L->V$ & 0.00 & 24.00 \\
\hline 251 & chr15:41701040 & Abra & $G \rightarrow C$ & $L->V$ & 0.00 & 27.27 \\
\hline 252 & chr15:54965030 & Deptor & $A->T$ & $M->L$ & 0.00 & 25.00 \\
\hline 253 & chr15:66523859 & $\mathrm{Tg}$ & $G \rightarrow>A$ & $V->1$ & 0.00 & 20.00 \\
\hline 254 & chr15:75937421 & Eppk1 & $C->T$ & $V->1$ & 0.00 & 25.00 \\
\hline 255 & chr15:76539950 & Recql4 & $A->G$ & $L->P$ & 0.00 & 20.00 \\
\hline 256 & chr15:95455328 & $\mathrm{Db} \times 2$ & $C->T$ & $V \rightarrow>M$ & 0.00 & 25.00 \\
\hline 257 & chr16:32756226 & Muc4 & $C->G$ & $\mathrm{Q}->\mathrm{E}$ & 0.00 & 24.32 \\
\hline 258 & chr16:32779211 & Muc4 & $C->A$ & $Q->K$ & 0.00 & 23.33 \\
\hline 259 & chr16:45577986 & Slc9a10 & $C->T$ & $A \rightarrow>V$ & 0.00 & 20.00 \\
\hline 260 & chr16:56668453 & Abi3bp & $C->A$ & $P \rightarrow Q$ & 0.00 & 22.22 \\
\hline 261 & chr16:58872574 & Olfr176 & $C->G$ & $\mathrm{~S}->\mathrm{T}$ & 0.00 & 20.59 \\
\hline 262 & chr17:6009735 & Synj2 & $\mathrm{T}->\mathrm{A}$ & $F->L$ & 0.00 & 25.81 \\
\hline 263 & chr17:6037828 & Synj2 & $C->G$ & $\mathrm{H} \rightarrow>\mathrm{D}$ & 0.00 & 25.00 \\
\hline 264 & chr17:7530924 & Tсp10a & $C \rightarrow T$ & $P \rightarrow S$ & 0.00 & 29.03 \\
\hline 265 & chr17:24111200 & Prss30 & $A \rightarrow C$ & $D->E$ & 0.00 & 21.05 \\
\hline 266 & chr17:24583771 & $\mathrm{E} 4 \mathrm{f1}$ & $C->T$ & $\mathrm{~S} \rightarrow>\mathrm{N}$ & 0.00 & 27.27 \\
\hline 267 & chr17:28021909 & Uhrf1bp1 & $\mathrm{G}->\mathrm{A}$ & $G \rightarrow D$ & 0.00 & 22.50 \\
\hline 268 & chr17:31365125 & Ubash3a & $C->T$ & $P \rightarrow S$ & 0.00 & 25.81 \\
\hline 269 & chr17:31392140 & Rsph1 & $G \rightarrow T$ & $P \rightarrow Q$ & 0.00 & 25.71 \\
\hline 270 & chr17:31398701 & Rsph1 & $G->A$ & $\mathrm{~T}->\mathrm{M}$ & 0.00 & 30.30 \\
\hline 271 & chr17:31754132 & Cbs & $\mathrm{T}->\mathrm{C}$ & $D->G$ & 0.00 & 29.03 \\
\hline 272 & chr17:32758655 & Gm9705 & $\mathrm{G}->\mathrm{A}$ & $V \rightarrow>M$ & 0.00 & 20.00 \\
\hline 273 & chr17:33158753 & Zfp763 & $C->T$ & $A \rightarrow>T$ & 0.00 & 22.86 \\
\hline 274 & chr17:33472542 & Zfp81 & $A \rightarrow G$ & $M->T$ & 0.00 & 27.59 \\
\hline 275 & chr17:34087468 & B3galt4 & $\mathrm{T}->\mathrm{C}$ & $\mathrm{N} \rightarrow>\mathrm{S}$ & 0.00 & 28.21 \\
\hline 276 & chr17:34338203 & Psmb8 & $G \rightarrow T$ & $A \rightarrow S$ & 0.00 & 28.57 \\
\hline 277 & chr17:34870392 & $C 4 b$ & $C->T$ & $R->Q$ & 0.00 & 22.58 \\
\hline 278 & chr17:34974426 & Dom3z & $\mathrm{T}->\mathrm{C}$ & $L \rightarrow S$ & 0.00 & 50.00 \\
\hline 279 & chr17:35267082 & Apom & $\mathrm{G} \rightarrow>\mathrm{T}$ & $\mathrm{Q}->\mathrm{K}$ & 0.00 & 43.33 \\
\hline 280 & chr17:35457904 & $\mathrm{H} 2-\mathrm{Q} 1$ & $C->T$ & $P->L$ & 0.00 & 32.50 \\
\hline 281 & chr17:36168621 & $\mathrm{H} 2-\mathrm{T} 23$ & $C->G$ & $\mathrm{R}->\mathrm{T}$ & 0.00 & 28.57 \\
\hline 282 & chr17:36218438 & $\mathrm{H} 2-\mathrm{Bl}$ & $\mathrm{T}->\mathrm{C}$ & $\mathrm{H} \rightarrow>\mathrm{R}$ & 0.00 & 27.03 \\
\hline 283 & chr17:36254622 & $\mathrm{H} 2-\mathrm{T} 10$ & $G \rightarrow>A$ & $P \rightarrow S$ & 0.00 & 33.33 \\
\hline 284 & chr17:36323554 & $\mathrm{H} 2-\mathrm{T} 3$ & $\mathrm{~T}->\mathrm{G}$ & $M->L$ & 0.00 & 21.67 \\
\hline 285 & chr17:43615815 & Mep1a & $\mathrm{T}->\mathrm{C}$ & $\mathrm{T}->\mathrm{A}$ & 0.00 & 25.00 \\
\hline 286 & chr17:43615911 & Mep1a & $\mathrm{T}->\mathrm{C}$ & $\mathrm{T}->\mathrm{A}$ & 0.00 & 30.00 \\
\hline 287 & chr17:43822205 & Сyp39a1 & $G \rightarrow>A$ & $G->R$ & 0.00 & 28.57 \\
\hline 288 & chr17:46161537 & Vegfa & $G \rightarrow A$ & $P->L$ & 0.00 & 37.04 \\
\hline 289 & chr17:46550212 & Zfp318 & $A->G$ & $E->G$ & 0.00 & 29.03 \\
\hline 290 & chr17:46635998 & BC048355 & $A \rightarrow C$ & $\mathrm{~K}->\mathrm{N}$ & 0.00 & 31.82 \\
\hline 291 & chr17:46893214 & Ptcra & $G \rightarrow>T$ & $R \rightarrow S$ & 0.00 & 37.14 \\
\hline 292 & chr17:72047254 & Fam179a & $\mathrm{T}->\mathrm{G}$ & $\mathrm{F}->\mathrm{C}$ & 0.00 & 37.50 \\
\hline 293 & chr17:80734673 & Arhgef33 & $\mathrm{G}->\mathrm{A}$ & $A \rightarrow>T$ & 0.00 & 26.67 \\
\hline 294 & chr17:88958139 & Klraq1 & $\mathrm{T}->\mathrm{C}$ & $M->T$ & 0.00 & 29.03 \\
\hline
\end{tabular}


Table 6 (continued)

\begin{tabular}{lllllll}
\hline$\#$ & Locus & Gene & Mutation & $\begin{array}{l}\text { Amino acid } \\
\text { change }\end{array}$ & Freq. IR- (\%) & Freq. IR+ (\%) \\
\hline 295 & chr17:89110812 & Gtf2a1l & G->A & R->Q & 0.00 & 31.03 \\
296 & chr17:89153211 & Lhcgr & $\mathrm{T}->\mathrm{C}$ & $\mathrm{T}->\mathrm{A}$ & 0.00 & 57.58 \\
297 & chr18:37907724 & Pcdhga10 & $\mathrm{C}->\mathrm{A}$ & $\mathrm{H}->\mathrm{N}$ & 0.00 & 26.09 \\
298 & chr18:38132920 & Arap3 & $\mathrm{G}->\mathrm{A}$ & $\mathrm{A}->\mathrm{V}$ & 0.00 & 44.83 \\
299 & chr18:60977711 & Tcof1 & $\mathrm{C}->\mathrm{A}$ & $\mathrm{A}->\mathrm{S}$ & 0.00 & 56.00 \\
300 & chr18:60992401 & Tcof1 & $\mathrm{C}->\mathrm{A}$ & $\mathrm{A}->\mathrm{S}$ & 0.00 & 46.43 \\
301 & chr18:65901869 & $5330437102 \mathrm{Rik}$ & $\mathrm{T}->\mathrm{C}$ & $\mathrm{F}->\mathrm{L}$ & 0.00 & 20.59 \\
302 & chr18:80326155 & Adnp2 & $\mathrm{A}->\mathrm{G}$ & $\mathrm{F}->\mathrm{L}$ & 0.00 & 26.83 \\
303 & chr18:80389581 & Rbfa & $\mathrm{C}->\mathrm{T}$ & $\mathrm{A}->\mathrm{T}$ & 0.00 & 32.35 \\
304 & chr19:10751147 & Pga5 & $\mathrm{C}->\mathrm{G}$ & $\mathrm{V}->\mathrm{L}$ & 0.00 & 45.83 \\
305 & chr19:11038598 & Ms4a10 & $\mathrm{C}->\mathrm{T}$ & $\mathrm{V}->\mathrm{I}$ & 0.00 & 20.69 \\
306 & chr19:18912582 & Trpm6 & $\mathrm{A}->\mathrm{G}$ & $\mathrm{M}->\mathrm{V}$ & 0.00 & 21.88 \\
307 & chr19:25696788 & Dmrt3 & $\mathrm{C}->\mathrm{T}$ & $\mathrm{T}->\mathrm{M}$ & 0.00 & 29.63 \\
308 & chr7:111207208 & Olfr643 & $\mathrm{G}->\mathrm{A}$ & $\mathrm{R}->$ * & 0.00 & 29.41 \\
\hline
\end{tabular}

$I R$ - control cells not irradiated, $I R+$ irradiated cells, $S N V$ single-nucleotide variants

indicating low fidelity of DNA damage repair [41]. Experiments in vitro and in mice derived from lv-iPSCs showed that this type of pluripotent cell tolerates genomic mutations better than the other cell types evaluated.

Although iPSCs resemble ESCs in morphology, gene expression profile and in vitro differentiation capacity, they differ substantially in genomic stability. The low fidelity of DNA repair observed in our study suggests that irradiation of lv-iPSCs induces a high rate of genomic abnormalities, which is less likely to trigger apoptosis in these cells and is therefore more likely to be tolerated, thus leading to a high rate of tumorigenesis in vivo. Compromised error-free HR pathway of DNA damage repair in lv-iPSCs may help explain the relatively high genomic instability in these cells. Indeed, inhibiting the HR pathway in iPSCs has been shown to destabilize the genome [61].
Our results suggest that the epigenetic status of iPSCs may contribute to, or modulate, their genomic instability. Variation in levels of H3K9me3 and phosphorylated ATM among iPSCs may mean that cells vary in their reliance on DNA damage repair pathways, which vary in their fidelity. Future studies should further examine the potential involvement of epigenetics and other factors in iPSC genomic instability.

Future work is also needed to clarify to what extent factors that are intrinsic or extrinsic to stem cells determine the risk of malignant transformation. Tomasetti et al. found that cancer risk in certain tissues correlated strongly with the number of divisions that the stem cells had undergone, suggesting that the accumulation of genomic mutations is primarily responsible for high risk of tumorigenesis [62]. Another study, in contrast, suggested that intrinsic factors account for only

(See figure on next page.)

Fig. 3 Gene expression levels in cells exposed or not to ionizing radiation (IR) for the indicated periods. a Heatmap showing Pearson's correlation coefficients relating expression levels between irradiated and non-irradiated cells. $\mathbf{b}$ Volcano plots of genes expressed in irradiated and non-irradiated cells, showing genes significantly up-regulated (red dots) or down-regulated (green dots) in irradiated cells. Differentially expressed genes were filtered based on FDR $<0.05$. c $\mathbf{d}$ Histograms of gene ontology classifications of differentially expressed genes in irradiated (c) ESCs and (d) iPSCs. e Heat maps showing the expression level of DNA damage repair-associated genes in irradiated (+) and non-irradiated (-) cells. Blue indicates lowest expression; fuchsia, highest. BER base excision repair, $H R$, homologous recombination, MMR mismatch repair, NER nucleotide excision repair, NHEJ non-homologous end joining 


\section{a}

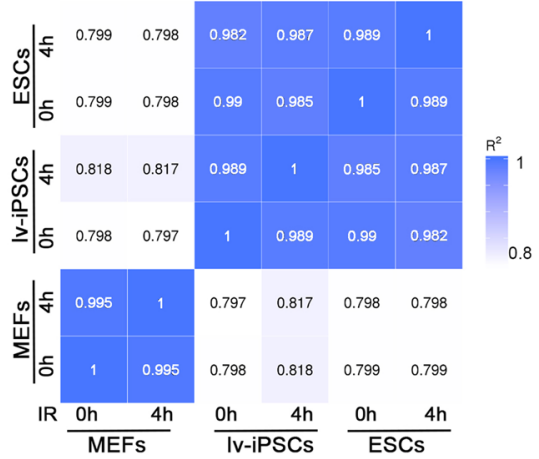

C Up-regulated genes in ESCS after IR

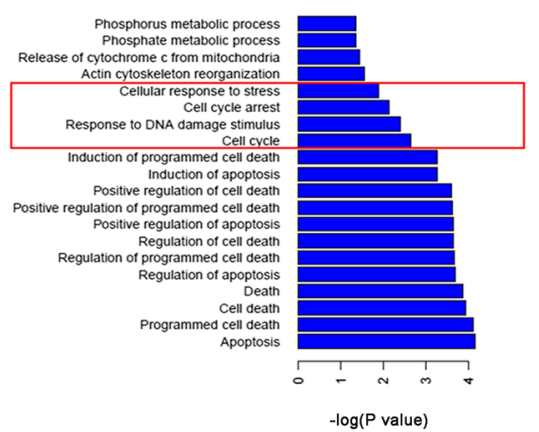

e

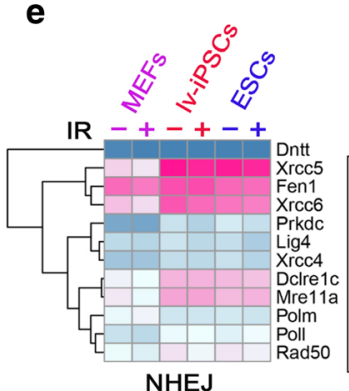

NHEJ

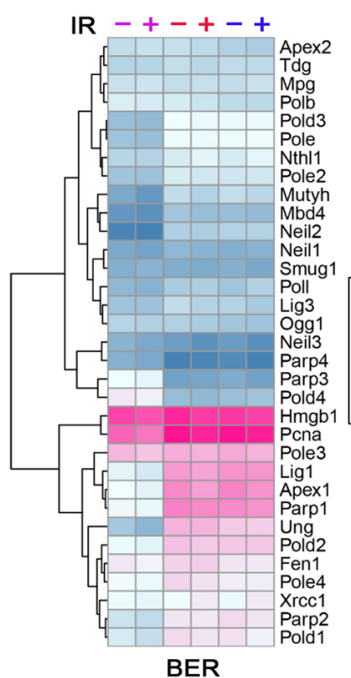

BER b

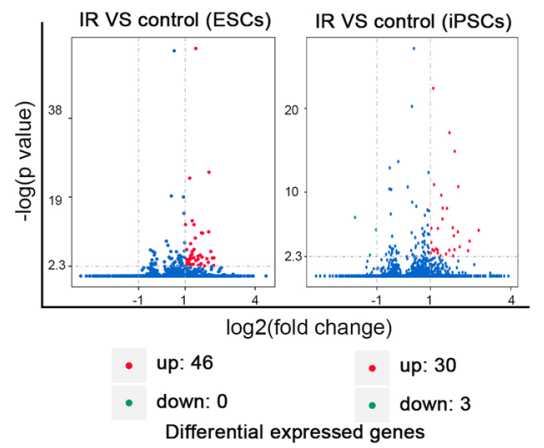

d

Up-regulated genes in iPSCS after IR

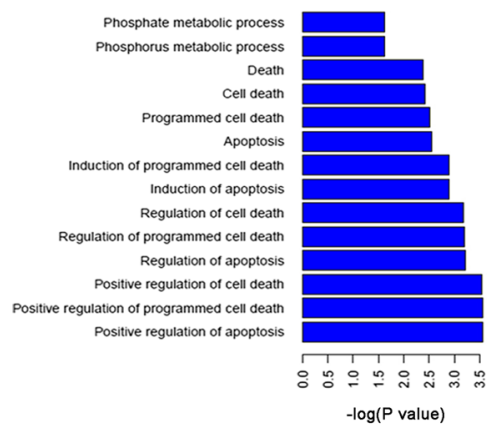

Color Key $\log ($ FPKM+1)

024468

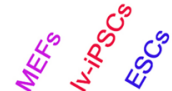

IR -+-+-+

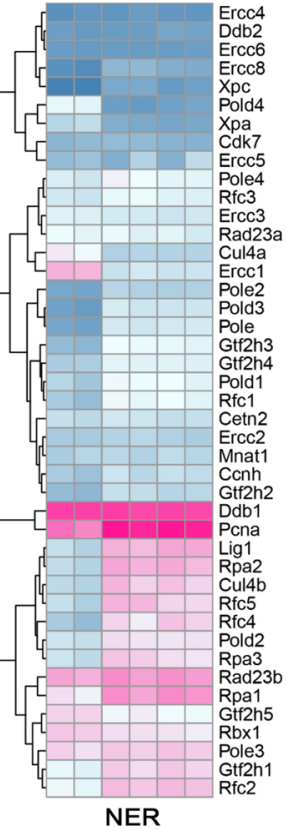




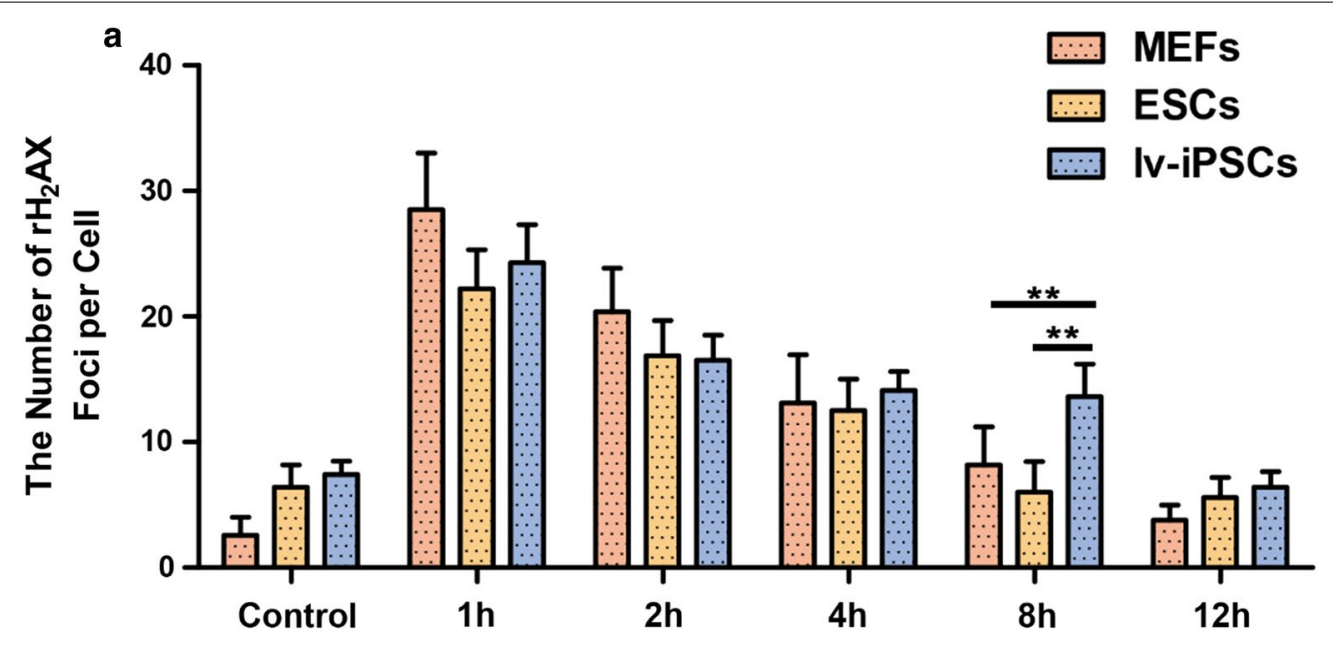

b

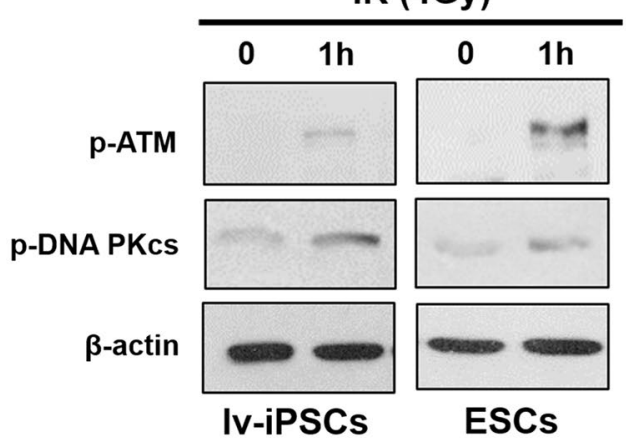

C

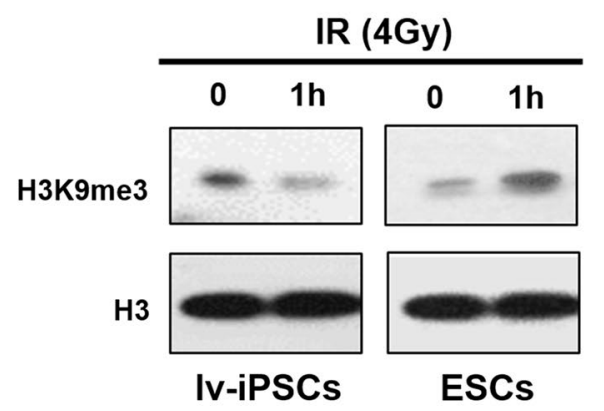

Fig. 4 The phosphorylation level of DNA repair-associated proteins. a Quantification of the numbers of $\gamma$-H2AX foci in IV-iPSCS, ESCs and MEFs. Error bars represent the standard error of the mean (SEM) for the numbers of $\mathrm{Y}-\mathrm{H} 2 \mathrm{AX}$ foci per nucleus based on $4-5$ fields, each containing approximately 20-30 cells. Significance of differences was assessed using Student's $t$ test. ${ }^{* *} \mathrm{P}<0.01$ (three independent experiments). $\mathbf{b}$ Western blot analysis of phosphorylated ATM (p-ATM) and phosphorylated catalytic subunit of DNA protein kinase (p-DNA-PKcs) in Iv-iPSCs and ESCs before and after ionizing irradiation. c Western blot analysis of the trimethylation level of H3K9 in Iv-iPSCs and ESCs before and after ionizing irradiation

$10 \%-30 \%$ of cancer risk, with the majority of the risk due to extrinsic factors [63]. The results from the present study suggest that extrinsic factors induce more genomic mutations than intrinsic factors in lv-iPSCs. The high rate of tumorigenesis of iPSCs in vivo suggests that extrinsic factors strongly contribute to cancer risk and carcinogenesis.

\section{Conclusions}

The present study demonstrated a low level of DNA damage repair in iPSCs. Ionizing radiation induced more somatic mutations and short indels in iPSCs than in ESCs or MEFs. Genome stability was higher in iPSCs induced chemically than in iPSCs induced with lentivirus. The high genome instability of lv-iPSCs appears to reflect 
a

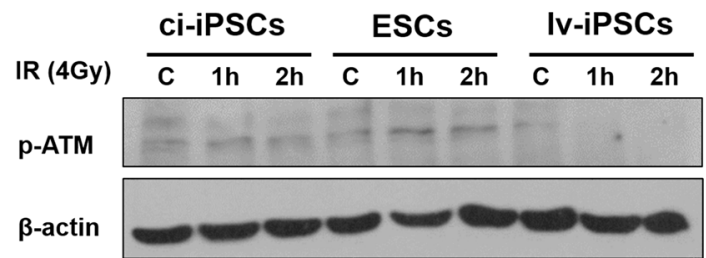

C

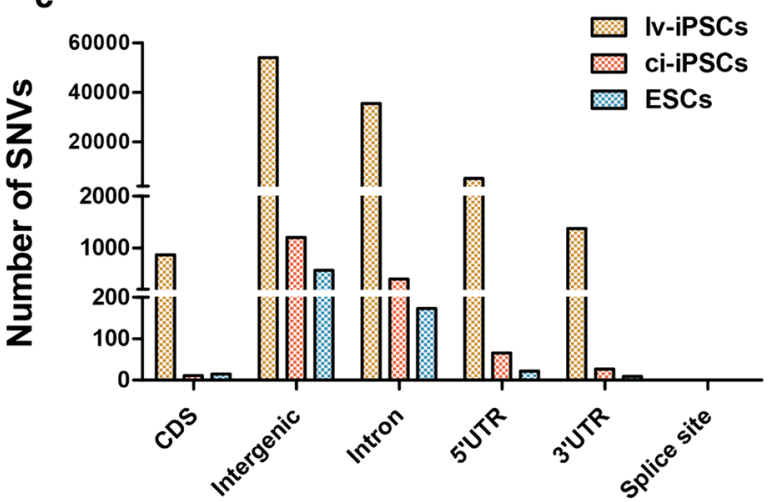

b

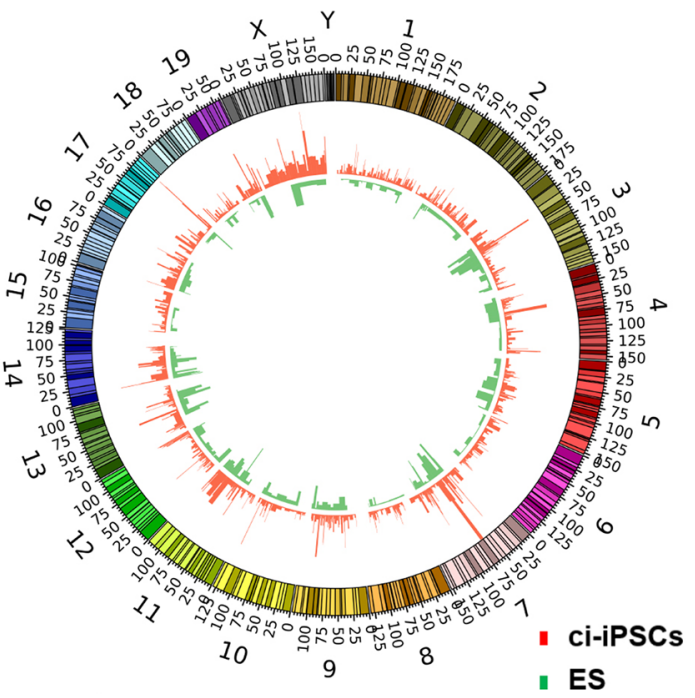

d

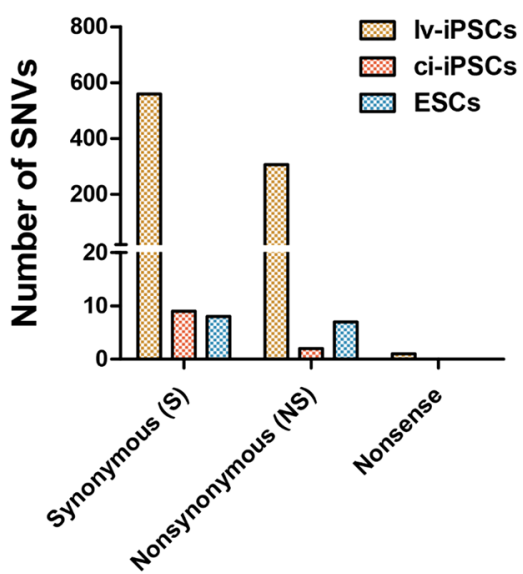

Fig. 5 High genome stability of ci-iPSCs. a Western blot analysis of phosphorylated ATM (p-ATM) in ci-iPS, Iv-iPS and ESCs before and after ionizing irradiation. b Circos plot showing genetic alterations in irradiated ci-iPSCs and ESCs, based on the corresponding untreated cells as a reference. Chromosome numbers are indicated as the outermost labels. $\mathbf{c}$ Histograms showing the number of SNVs in each genomic region of irradiated Iv-iPSCs, ci-iPSCs and MEFs. CDS coding sequence, SNV single-nucleotide variants, UTR untranslated region. $\mathbf{d}$ Histograms showing the numbers of SNVs in the coding regions of irradiated IV-iPSCs, ci-iPSCs and MEFs 


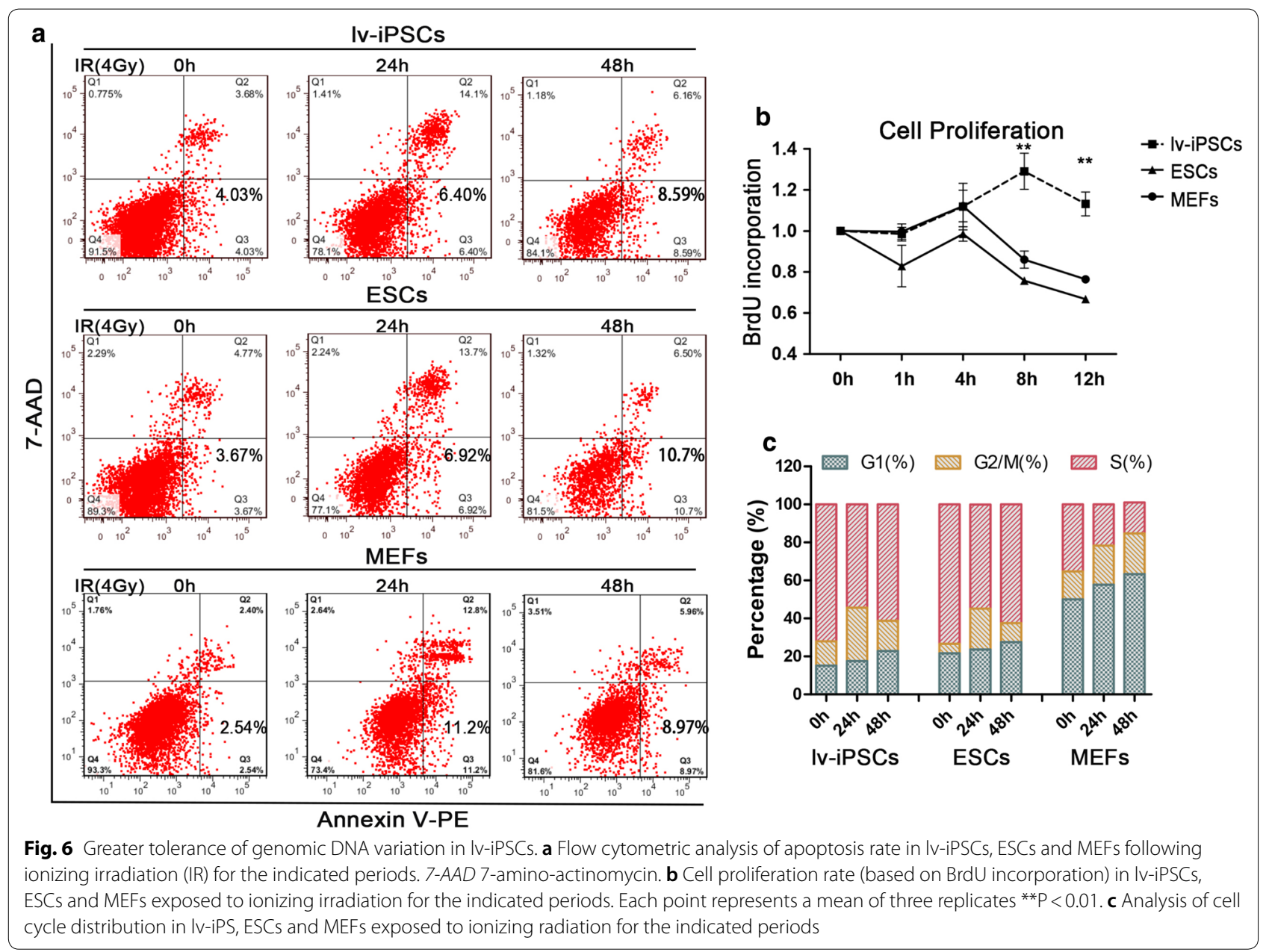


a

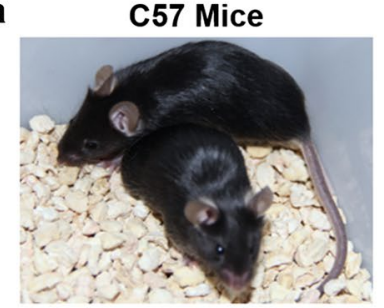

b

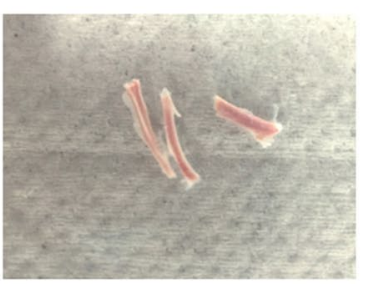

C

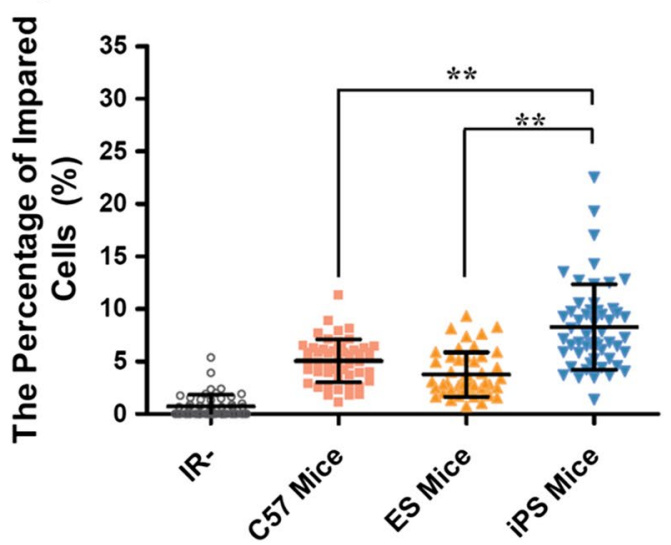

ES Mice
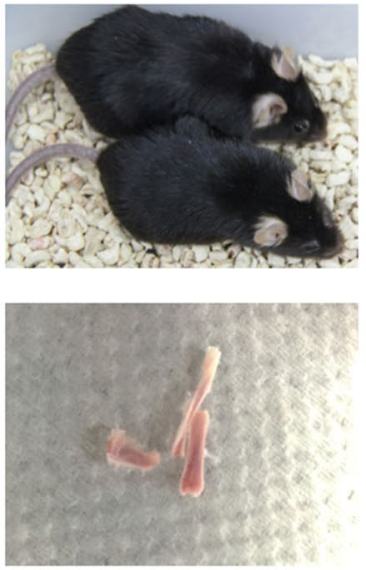

d
iPS Mice
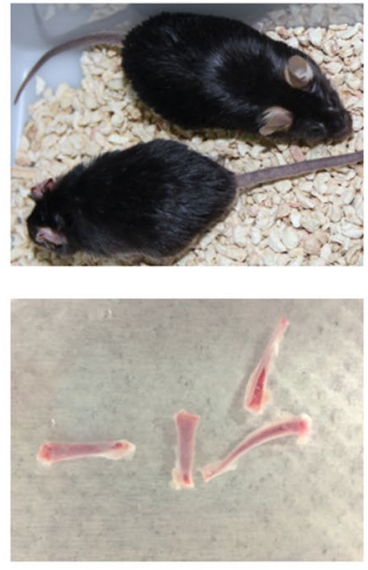

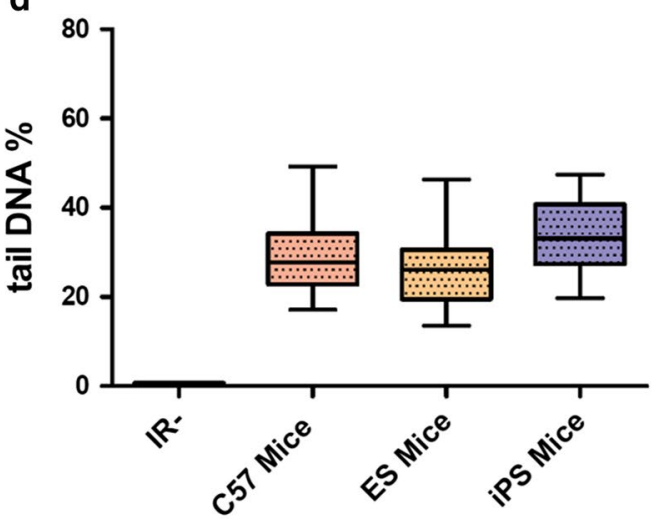

Fig. 7 Genome stability of mice derived from Iv-iPSCs or ESCs following exposure to ionizing radiation (IR). Controls were C57 mice. a Mice were generated from IV-iPSCs or ESCs through tetraploid embryo complementation. Representative results from three independent experiments are shown. $\mathbf{b}$ Examples of bones from the three types of mice, from which marrow cells were extracted. $\mathbf{c}$ Box plots showing the percentage of impaired bone marrow cells in each mouse strain. DNA damage was evaluated using single-cell gel electrophoresis **P $<0.01$. d Box plots showing the percentage of Tail DNA in impaired cells as a measure of DNA damage. Tail DNA\%=Tail DNA intensity/Cell DNA Intensity $\times 100 \%$. CASP software was used to calculate tail moment based on 50-100 randomly selected cells per sample 


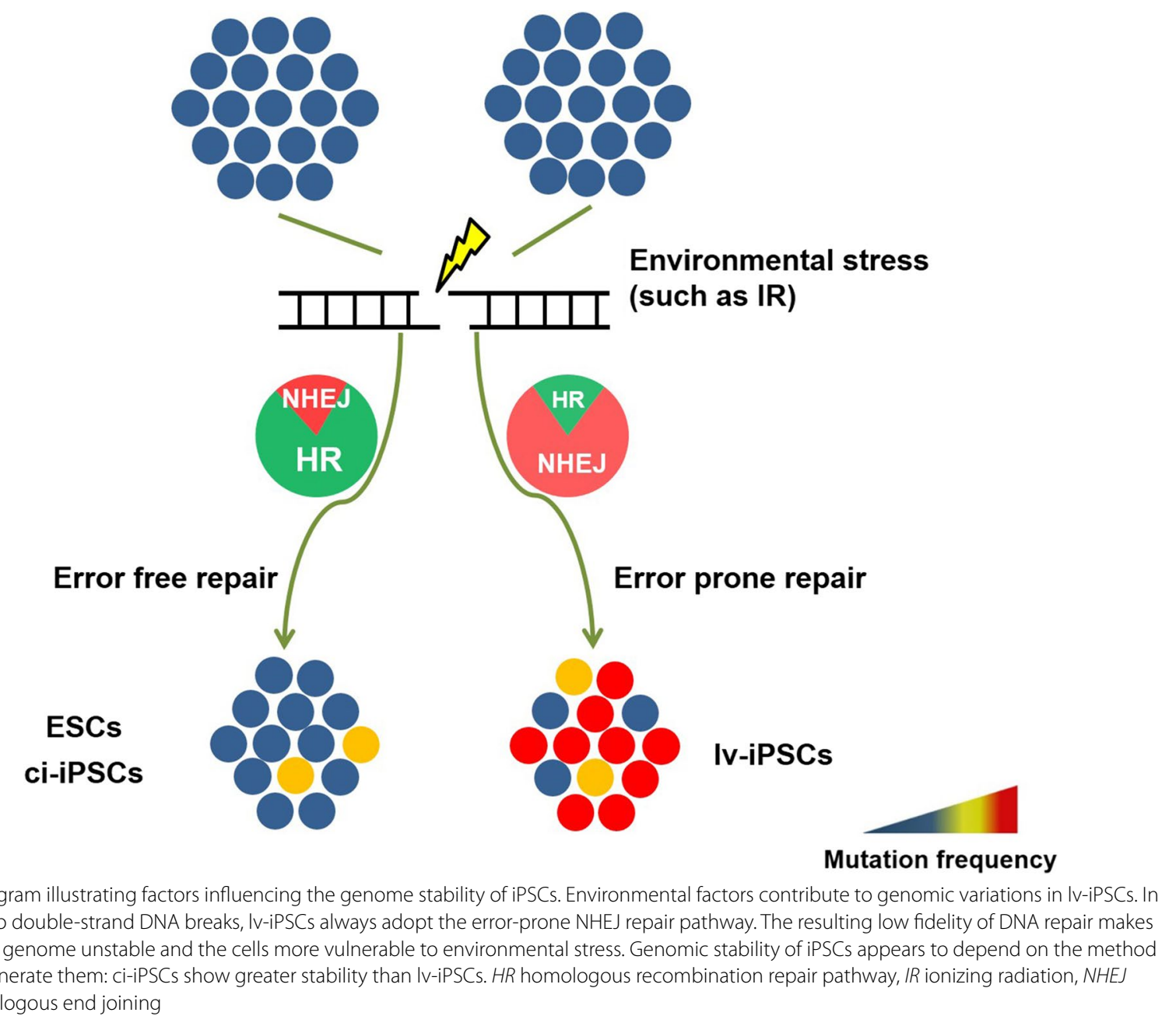

increased NHEJ and decreased HR pathways of DNA damage repair, and could contribute to the high rate of tumorigenesis in vivo.

\section{Authors' contributions}

YS, QZ and JC conceived this study. MZ and LW contributed to its design. $M Z, G L, K A, C Y, H L, F D, X H$ and $Y L$ performed experiments, while $M Z$ and $G L$ performed bioinformatic analyses. JC assisted with bioinformatic analysis and interpretation. YS and MZ interpreted the data and wrote the paper with the assistance of the other authors. QZ, DP, and XX provided critical technical assistance and expertise. All authors read and approved the final manuscript.

\section{Author details}

1 Key Laboratory of Genomic and Precision Medicine, China Gastrointestinal Cancer Research Center, Beijing Institute of Genomics, Chinese Academy of Sciences, Beijing 100101, P. R. China. ${ }^{2}$ University of Chinese Academy of Sciences, Beijing 100049, P. R. China. ${ }^{3}$ State Key Laboratory of Stem Cell and Reproductive Biology, Institute of Zoology, Chinese Academy of Sciences, Beijing 100101, P. R. China. ${ }^{4}$ The Key Laboratory of Regenerative Biology, Guangdong Provincial Key Laboratory of Stem Cell and Regenerative Medicine, South China Institute for Stem Cell Biology and Regenerative Medicine, Guangzhou Institutes of Biomedicine and Health, Chinese Academy of Sciences, Guangzhou 510530, P. R. China. ${ }^{5}$ CAS Key Laboratory of Receptor
Research, the National Center for Drug Screening, Shanghai Institute of Materia Medica, Chinese Academy of Sciences, Shanghai 201203, P. R. China.

\section{Acknowledgements}

We thank Professor Qi Zhou from the Institute of Zoology of the Chinese Academy of Sciences for generously supplying iPS- and ES-derived mice. We thank Professor Duanqing Pei from the Guangzhou Institutes of Biomedicine and Health of the Chinese Academy of Sciences for providing the Iv-iPSC line, and Xin Xie from the Shanghai Institute of Materia Medica of the Chinese Academy of Sciences for providing the ci-iPSC line. We are also grateful to our laboratory colleagues for their assistance with experiments and manuscript preparation.

\section{Competing interests}

The authors declare that they have no competing interests.

\section{Availability of data and materials}

The raw sequencing data reported in this manuscript are publicly available at the Genome Sequence Archive (http://gsa.big.ac.cn) under Accession Number CRA000695.

All data generated and analyzed are included in the article to support the conclusions. 


\section{Consent for publication}

Not applicable.

\section{Ethics approval and consent to participate}

This study was approved by the Ethics Committee of the Beijing Institute of Genomics and the School of Life Sciences at the Chinese Academy of Sciences.

\section{Funding}

This work was supported by the Precision Medicine Research Program of the Chinese Academy of Sciences (KJZD-EW-L14), Strategic Priority Research Program of the Chinese Academy of Sciences (XDA01040407), National Natural Science Foundation of China (31471395, 91019024, 31540033 and 31100558), National Basic Research Program of China (973 Program, 2012CB518302 and 2013CB911001) and 100 Talents Project.

\section{Received: 31 October 2017 Accepted: 11 June 2018}

Published online: 25 July 2018

\section{References}

1. Thomson JA, Itskovitz-Eldor J, Shapiro SS, Waknitz MA, Swiergiel JJ, Marshall VS, et al. Embryonic stem cell lines derived from human blastocysts. Science. 1998;282(5391):1145-7.

2. Takahashi K, Yamanaka S. Induction of pluripotent stem cells from mouse embryonic and adult fibroblast cultures by defined factors. Cell. 2006;126(4):663-76.

3. de Lazaro I, Yilmazer A, Kostarelos K. Induced pluripotent stem (iPS) cells: a new source for cell-based therapeutics? J Control Release. 2014:185:37-44.

4. Amabile G, Meissner A. Induced pluripotent stem cells: current progress and potential for regenerative medicine. Trends Mol Med. 2009;15(2):59-68.

5. Yamanaka S. A fresh look at iPS cells. Cell. 2009:137(1):13-7.

6. Meyer N, Penn LZ. Reflecting on 25 years with MYC. Nat Rev Cancer 2008;8(12):976-90.

7. Ben-Porath I, Thomson MW, Carey VJ, Ge R, Bell GW, Regev A, et al. An embryonic stem cell-like gene expression signature in poorly differentiated aggressive human tumors. Nat Genet. 2008;40(5):499-507.

8. Malchenko S, Galat V, Seftor EA, Vanin EF, Costa FF, Seftor RE, et al. Cancer hallmarks in induced pluripotent cells: new insights. J Cell Physiol. 2010;225(2):390-3.

9. Rowland BD, Peeper DS. KLF4, p21 and context-dependent opposing forces in cancer. Nat Rev Cancer. 2006;6(1):11-23.

10. Ghosh Z, Huang M, Hu S, Wilson KD, Dey D, Wu JC. Dissecting the oncogenic and tumorigenic potential of differentiated human induced pluripotent stem cells and human embryonic stem cells. Cancer Res. 2011;71(14):5030-9.

11. Blasco MA, Serrano M, Fernandez-Capetillo O. Genomic instability in iPS: time for a break. EMBO J. 2011;30(6):991-3.

12. Pasi CE, Dereli-Oz A, Negrini S, Friedli M, Fragola G, Lombardo A, et al. Genomic instability in induced stem cells. Cell Death Differ. 2011;18(5):745-53.

13. Pera MF. Stem cells: the dark side of induced pluripotency. Nature 2011;471(7336):46-7.

14. Ronen D, Benvenisty N. Genomic stability in reprogramming. Curr Opin Genet Dev. 2012;22(5):444-9.

15. Sarig R, Rotter V. Can an iPS cell secure its genomic fidelity? Cell Death Differ. 2011;18(5):743-4.

16. von Joest M, Bua Aguin S, Li H. Genomic stability during cellular reprogramming: mission impossible? Mutat Res. 2016;788:12-6.

17. Friedberg EC. A history of the DNA repair and mutagenesis field The discovery of base excision repair. DNA Repair. 2016:37:A35-9.

18. Lieber MR. The mechanism of human nonhomologous DNA end joining. J Biol Chem. 2008;283(1):1-5.

19. Filippo JS, Sung P, Klein H. Mechanism of eukaryotic homologous recombination. Annu Rev Biochem. 2008:77:229-57.
20. Weeden CE, Chen YS, Ma SB, Hu YF, Ramm G, Sutherland KD, et al. Lung basal stem cells rapidly repair DNA damage using the error-prone nonhomologous end-joining pathway. PLoS Biol. 2017;15(1):e2000731.

21. Long $Y$, Wang M, Gu HF, Xie X. Bromodeoxyuridine promotes fullchemical induction of mouse pluripotent stem cells. Cell Res. 2015;25(10):1171-4.

22. Jackson SP. Sensing and repairing DNA double-strand breaks. Carcinogenesis. 2002;23(5):687-96.

23. Khanna KK, Jackson SP. DNA double-strand breaks: signaling, repair and the cancer connection. Nat Genet. 2001;27(3):247-54.

24. Lombard DB, Chua KF, Mostoslavsky R, Franco S, Gostissa M, Alt FW. DNA repair, genome stability, and aging. Cell. 2005;120(4):497-512.

25. Zha S, Alt FW, Cheng HL, Brush JW, Li G. Defective DNA repair and increased genomic instability in Cernunnos-XLF-deficient murine ES cells. Proc Natl Acad Sci USA. 2007;104(11):4518-23.

26. Rooney S, Alt FW, Lombard D, Whitlow S, Eckersdorff M, Fleming J, et al. Defective DNA repair and increased genomic instability in artemis-deficient murine cells. J Exp Med. 2003:197(5):553-65.

27. Esteban MA, Wang T, Qin BM, Yang JY, Qin DJ, Cai JL, et al. Vitamin C enhances the generation of mouse and human induced pluripotent stem cells. Cell Stem Cell. 2010;6(1):71-9.

28. Zhang M, Yang C, Liu H, Sun Y. Induced pluripotent stem cells are sensitive to DNA damage. Genomics Proteomics Bioinf. 2013;11(5):320-6.

29. Huangfu DW, Maehr R, Guo WJ, Eijkelenboom A, Snitow M, Chen $A E$, et al. Induction of pluripotent stem cells by defined factors is greatly improved by small-molecule compounds. Nat Biotechnol. 2008;26(7):795-7.

30. Sun Y, Xu Y, Roy K, Price BD. DNA damage-induced acetylation of lysine 3016 of ATM activates ATM kinase activity. Mol Cell Biol. 2007;27(24):8502-9.

31. Li H, Durbin R. Fast and accurate short read alignment with BurrowsWheeler transform. Bioinformatics. 2009;25(14):1754-60.

32. Li H, Handsaker B, Wysoker A, Fennell T, Ruan J, Homer N, et al. The sequence alignment/map format and SAMtools. Bioinformatics. 2009;25(16):2078-9.

33. McKenna A, Hanna M, Banks E, Sivachenko A, Cibulskis K, Kernytsky A, et al. The genome analysis toolkit: a MapReduce framework for analyzing next-generation DNA sequencing data. Genome Res. 2010;20(9):1297-303.

34. Kim D, Pertea G, Trapnell C, Pimentel H, Kelley R, Salzberg SL. TopHat2: accurate alignment of transcriptomes in the presence of insertions, deletions and gene fusions. Genome Biol. 2013;14(4):R36.

35. Langmead B, Salzberg SL. Fast gapped-read alignment with Bowtie 2. Nat Methods. 2012;9(4):357-9.

36. Trapnell C, Roberts A, Goff L, Pertea G, Kim D, Kelley DR, et al. Differential gene and transcript expression analysis of RNA-seq experiments with TopHat and Cufflinks. Nat Protoc. 2012;7(3):562-78.

37. Gentleman RC, Carey VJ, Bates DM, Bolstad B, Dettling M, Dudoit S, et al. Bioconductor: open software development for computational biology and bioinformatics. Genome Biol. 2004;5(10):R80.

38. Zhao XY, Lv Z, Li W, Zeng F, Zhou Q. Production of mice using iPS cells and tetraploid complementation. Nat Protoc. 2010;5(5):963-71.

39. Shu J, Zhang $K$, Zhang MJ, Yao AZ, Shao SD, Du FX, et al. GATA family members as inducers for cellular reprogramming to pluripotency. Cell Res. 2015:25(2):169-80.

40. Johnson RD, Jasin M. Double-strand-break-induced homologous recombination in mammalian cells. Biochem Soc Trans. 2001:29(Pt 2):196-201.

41. Lavin MF, Birrell G, Chen P, Kozlov S, Scott S, Gueven N. ATM signaling and genomic stability in response to DNA damage. Mutat Res. 2005;569(1-2):123-32

42. Takahashi K, Tanabe K, Ohnuki M, Narita M, Ichisaka T, Tomoda K, et al. Induction of pluripotent stem cells from adult human fibroblasts by defined factors. Cell. 2007;131(5):861-72.

43. Stadtfeld M, Nagaya M, Utikal J, Weir G, Hochedlinger K. Induced pluripotent stem cells generated without viral integration. Science. 2008;322(5903):945-9.

44. Kaji K, Norrby K, Paca A, Mileikovsky M, Mohseni P, Woltjen K. Virus-free induction of pluripotency and subsequent excision of reprogramming factors. Nature. 2009:458(7239):771-5. 
45. Woltjen K, Michael IP, Mohseni P, Desai R, Mileikovsky M, Hamalainen R, et al. piggyBac transposition reprograms fibroblasts to induced pluripotent stem cells. Nature. 2009;458(7239):766-70.

46. Zhou W, Freed CR. Adenoviral gene delivery can reprogram human fibroblasts to induced pluripotent stem cells. Stem Cells. 2009;27(11):2667-74.

47. Zhou H, Wu S, Joo JY, Zhu S, Han DW, Lin T, et al. Generation of induced pluripotent stem cells using recombinant proteins. Cell Stem Cell. 2009;4(5):381-4.

48. Warren L, Manos PD, Ahfeldt T, Loh Y-H, Li H, Lau F, et al. Highly efficient reprogramming to pluripotency and directed differentiation of human cells with synthetic modified mRNA. Cell Stem Cell. 2010;7(5):618-30.

49. Miyoshi N, Ishii H, Nagano H, Haraguchi N, Dewi DL, Kano Y, et al. Reprogramming of mouse and human cells to pluripotency using mature microRNAs. Cell Stem Cell. 2011;8(6):633-8.

50. Hou PP, Li YQ, Zhang X, Liu C, Guan JY, Li HG, et al. Pluripotent stem cells induced from mouse somatic cells by small-molecule compounds. Science. 2013;341(6146):651-4.

51. Shu J, Wu C, Wu Y, Li Z, Shao S, Zhao W, et al. Induction of pluripotency in mouse somatic cells with lineage specifiers. Cell. 2013;153(5):963-75.

52. Stadtfeld M, Apostolou E, Akutsu H, Fukuda A, Follett P, Natesan S, et al. Aberrant silencing of imprinted genes on chromosome 12qF1 in mouse induced pluripotent stem cells. Nature. 2010;465(7295):175-81.

53. Laurent LC, Ulitsky I, Slavin I, Tran H, Schork A, Morey R, et al. Dynamic changes in the copy number of pluripotency and cell proliferation genes in human ESCS and iPSCs during reprogramming and time in culture. Cell Stem Cell. 2011;8(1):106-18.

54. Mayshar Y, Ben-David U, Lavon N, Biancotti JC, Yakir B, Clark AT, et al. Identification and classification of chromosomal aberrations in human induced pluripotent stem cells. Cell Stem Cell. 2010;7(4):521-31.
55. Lister R, Pelizzola M, Kida YS, Hawkins RD, Nery JR, Hon G, et al. Hotspots of aberrant epigenomic reprogramming in human induced pluripotent stem cells. Nature. 2011;471(7336):68-73.

56. Polo JM, Liu S, Figueroa ME, Kulalert W, Eminli S, Tan KY, et al. Cell type of origin influences the molecular and functional properties of mouse induced pluripotent stem cells. Nat Biotechnol. 2010;28(8):848-55.

57. Gore A, Li Z, Fung HL, Young JE, Agarwal S, Antosiewicz-Bourget J, et al. Somatic coding mutations in human induced pluripotent stem cells. Nature. 2011:471(7336):63-7.

58. Kim K, Doi A, Wen B, Ng K, Zhao R, Cahan P, et al. Epigenetic memory in induced pluripotent stem cells. Nature. 2010:467(7313):285-90.

59. Kim K, Zhao R, Doi A, Ng K, Unternaehrer J, Cahan P, et al. Donor cell type can influence the epigenome and differentiation potential of human induced pluripotent stem cells. Nat Biotechnol. 2012;30(1):1117-9.

60. Gao S, Zheng C, Chang G, Liu W, Kou X, Tan K, et al. Unique features of mutations revealed by sequentially reprogrammed induced pluripotent stem cells. Nat Commun. 2015;6:6318.

61. Thompson LH, Schild D. The contribution of homologous recombination in preserving genome integrity in mammalian cells. Biochimie. 1999;81(1-2):87-105

62. Tomasetti C, Vogelstein B. Cancer etiology. Variation in cancer risk among tissues can be explained by the number of stem cell divisions. Science. 2015;347(6217):78-81.

63. Wu S, Powers S, Zhu W, Hannun YA. Substantial contribution of extrinsic risk factors to cancer development. Nature. 2016;529(7584):43-7.

Ready to submit your research? Choose BMC and benefit from:

- fast, convenient online submission

- thorough peer review by experienced researchers in your field

- rapid publication on acceptance

- support for research data, including large and complex data types

- gold Open Access which fosters wider collaboration and increased citations

- maximum visibility for your research: over $100 \mathrm{M}$ website views per year

At BMC, research is always in progress.

Learn more biomedcentral.com/submissions 